\title{
A literature review of dopamine in binge eating
}

\author{
Yang Yu ${ }^{1^{*}} \mathbb{D}$, Renee Miller ${ }^{2}$ and Susan W. Groth ${ }^{1}$
}

\begin{abstract}
Objective: Binge eating, a core diagnostic symptom in binge eating disorder and bulimia nervosa, increases the risk of multiple physiological and psychiatric disorders. The neurotransmitter dopamine is involved in food craving, decision making, executive functioning, and impulsivity personality trait; all of which contribute to the development and maintenance of binge eating. The objective of this paper is to review the associations of dopamine levels/activities, dopamine regulator (e.g., dopamine transporter, degrading enzymes) levels/activities, and dopamine receptor availability/affinity with binge eating.
\end{abstract}

Methods: A literature search was conducted in PubMed and PsycINFO to obtain human and animal studies published since 2010.

Results: A total of 31 studies (25 human, six animal) were included. Among the human studies, there were 12 casecontrol studies, eight randomized controlled trials, and five cross-sectional studies. Studies used neuroimaging (e.g., positron emission tomography), genetic, and pharmacological (e.g., dopamine transporter inhibitor) techniques to describe or compare dopamine levels/activities, dopamine transporter levels/activities, dopamine degrading enzyme (e.g., catechol-O-methyltransferase) levels/activities, and dopamine receptor (e.g., D1, D2) availability/affinity among participants with and without binge eating. Most human and animal studies supported an altered dopaminergic state in binge eating $(26 / 31,83.9 \%)$; however, results were divergent regarding whether the altered state was hyperdopaminergic $(9 / 26,34.6 \%)$ or hypodopaminergic $(17 / 26,65.4 \%)$. The mixed findings may be partially explained by the variability in sample characteristics, study design, diagnosis criteria, and neuroimaging/genetic/pharmacological techniques used. However, it is possible that instead of being mutually exclusive, the hyperdopaminergic and hypodopaminergic state may co-exist, but in different stages of binge eating or in different individual genotypes.

Conclusions: For future studies to clarify the inconsistent findings, a homogenous sample that controls for confounders that may influence dopamine levels (e.g., psychiatric diseases) is preferable. Longitudinal studies are needed to evaluate whether the hyper- and hypo-dopaminergic states co-exist in different stages of binge eating or co-exist in individual phenotypes.

Plain Language Summary: Binge eating is characterized by eating a large amount of food in a short time and a feeling of difficulty to stop while eating. Binge eating is the defining symptom of binge eating disorder and bulimia nervosa, both of which are associated with serious health consequences. Studies have identified several psychological risk factors of binge eating, including a strong desire for food, impaired cognitive skills, and distinct personality traits (e.g., quick action without careful thinking). However, the physiological markers of binge eating remain unclear.

*Correspondence: yang_yu@urmc.rochester.edu

1 School of Nursing, University of Rochester, 601 Elmwood Avenue, Rochester, NY 14642, USA

Full list of author information is available at the end of the article permits use, sharing, adaptation, distribution and reproduction in any medium or format, as long as you give appropriate credit to the original author(s) and the source, provide a link to the Creative Commons licence, and indicate if changes were made. The images or other third party material in this article are included in the article's Creative Commons licence, unless indicated otherwise in a credit line to the material. If material is not included in the article's Creative Commons licence and your intended use is not permitted by statutory regulation or exceeds the permitted use, you will need to obtain permission directly from the copyright holder. To view a copy of this licence, visit http://creativecommons.org/licenses/by/4.0/. The Creative Commons Public Domain Dedication waiver (http://creativeco mmons.org/publicdomain/zero/1.0/) applies to the data made available in this article, unless otherwise stated in a credit line to the data. 
Dopamine is a neurotransmitter that is heavily involved in feeding behavior, human motivation, cognitive ability, and personality. Therefore, dopamine is believed to play a critical role in binge eating. This review synthesized study findings related to the levels and activities of dopamine, dopamine regulators, and dopamine receptors in the context of binge eating. The primary finding is that most studies that used neuroimaging, genetic, or drug techniques found an altered dopaminergic state related to binge eating. However, the literature is inconsistent concerning the direction of the alteration. Considering the mixed findings and the limitations in study design, future studies, especially those that include repeated measurements, are needed to clarify the role of dopamine in binge eating.

Keywords: Bing eating disorder, Bulimia nervosa, Neurophysiology, Hyperdopaminergic state, Hypodopaminergic state

\section{Introduction}

Binge eating, a core diagnostic symptom in binge eating disorder (BED) and bulimia nervosa $(\mathrm{BN})$, is characterized by eating a large amount of food in a short time and a sense of loss of control while eating [1]. Binge eating (with or without diagnosed BED or BN) affects $10-40 \%$ of children and adults [2, 3], and it is a strong predictor of obesity and increases the risk of multiple physiological (e.g., metabolic syndrome, malnutrition) and psychiatric (e.g., depression) disorders [4, 5]. Despite the high prevalence and negative consequences, many patients with binge eating remain undiagnosed and untreated [6]. Even among those who are diagnosed and receive the most validated cognitive-behavioral therapy, $60 \%$ of them fail to fully abstain from binge eating [7]. To facilitate early diagnosis and to inform the development of novel treatment strategies, there is a critical need to identify the biomarkers that are involved in the development and maintenance of binge eating.

Enhanced food craving, impaired decision making, diminished executive function, and impulsivity personality traits are among the main risk factors that drive or perpetuate binge eating. Food craving is an intense desire or motivation to consume food, and it has been consistently associated with more frequent or more severe binge eating behaviors in cross-sectional and prospective studies $[8,9]$. Decision making is regulated by two distinct systems: goal-directed (flexible, behaviors are adjusted based on anticipated outcomes) and habitual (automatic, behaviors are based on previous learning). There is converging evidence that binge eating is associated with an imbalance between these two systems with a greater reliance on habitual control [10-12]. Executive function refers to a set of high-order cognitive abilities that allow a person to perform complex daily activities. A large body of literature has supported that deficits in the three main components of executive function, including working memory, inhibitory control, and cognitive flexibility, contribute to binge eating symptoms $[13,14]$. Finally, impulsivity as a personality dimension is generally described as a tendency to engage in premature behaviors without sufficient consideration of possible consequences, and it has been strongly related to the loss of control experienced during binge eating episodes $[15,16]$.

Food craving, decision making, executive function, and impulsivity are regulated by distinguishable, although somewhat overlapping, brain regions and neurocircuitry. For example, a large brain network including the ventral tegmental area, ventral striatum (nucleus accumbens), lateral hypothalamus, orbitofrontal cortex, and amygdala is involved in the excursion of food craving. In contrast, the dorsal striatum, which can be further divided into dorsomedial striatum (caudate) and dorsolateral striatum (putamen), is essential for orchestrating goal-directed and habitual decision making [17, 18]. Furthermore, the prefrontal cortex, especially the lateral prefrontal cortex, is the major neural substrate of executive function. In terms of impulsivity, although its brain structural correlates have not been clarified, it is believed that various regions, including the striatum, prefrontal cortex, hippocampus, anterior cingulate cortex, temporal pole, and insula, are involved [15].

The neurotransmitter dopamine has attracted growing attention in the field of binge eating due to its widely distributed receptors in the brain regions and neurocircuitry implicated in food craving, decision making, executive function, and impulsivity, as well as its functional associations with these risk factors.

Dopamine is synthesized and released by dopamine neurons located in three main areas in the midbrain: the ventral tegmental area, the substantia nigra, and the retrorubral field [19]. Dopamine neurons in the ventral tegmental area send projections to the ventral striatum (the main brain region relevant to food craving), forming the mesolimbic circuits [19]. The mesolimbic dopaminergic system has traditionally been associated with motivation. In the context of eating behaviors, the hyperactive mesolimbic dopaminergic system leads to an increased incentive salience or craving for food-related rewards, thus contributing to the initiation of food consumption [20-23]. In addition to sending projections to the ventral striatum, midbrain dopamine neurons in the ventral 
tegmental area further project to the prefrontal cortex (the main brain region responsible for executive function), via the mesocortical pathway. Dopamine in the prefrontal cortex serves as a neuromodulator that is essential for regulating inhibitory control, working memory, and set-shifting. For example, neuroimaging and pharmacological studies have provided evidence that dopamine agonists increase frontal cerebral blood flow, which is associated with better inhibitory control [24, 25]. Additionally, an inverted-U relationship of dopamine with working memory and set-shifting has been repeatedly reported such that too low or too high extracellular dopamine concentration in the prefrontal cortex can impair working memory and set-shifting [26-28]. In contrast, dopamine neurons in the substantia nigra send projections to the dorsal striatum (the key hub for the regulation of goal-directed and habitual decision making), forming the nigrostriatal circuits. Substantial evidence from animal studies has demonstrated that dopamine sensitization in the dorsal striatum accelerates the development of habit formation from previously goal-directed behaviors [29-31]. Finally, studies have found that a high magnitude of dopamine release or higher dopamine receptor capability in the striatum predicts higher levels of impulsivity in humans and animals [32,33]. The major dopaminergic pathways and corresponding risk factors of binge eating are outlined in Fig. 1.

After being synthesized in the dopamine neurons and released into the synapse cleft, dopamine functions through binding to its receptors, generally distinct in two main subclasses: D1-like (D1 and D5 receptors) and D2-like (D2, D3, and D4 receptors) [34]. D1 and D2 receptors are abundant in the striatum and prefrontal cortex [34, 35], and they are the most studied in terms of regulating food craving, decision making, and executive functioning $[36,37]$.

The termination of dopamine function largely relies on dopamine clearance by the dopamine transporter, which drives the reuptake of extracellular dopamine into presynaptic neurons and consequently decreases the synaptic dopamine levels. Additionally, dopamine is degraded by enzymes such as monoamine oxidase and catecholO-methyltransferase (COMT). COMT is most abundant in the prefrontal cortex and accounts for over $60 \%$ of the metabolic degradation of released dopamine in the prefrontal cortex [38]. While a detailed description of dopamine neurons, receptors, transporters, and degrading enzymes is beyond the scope of this paper, they have been extensively reviewed elsewhere [35, 39].

The role of dopamine in binge eating has been previously reviewed; however, these reviews were predominantly published between 2010 and 2015 [40-45]. Importantly, these reviews were either exclusively focused on animal models $[40,43]$ or included very few $(<5)$ human studies [41, 42, 44, 45]. Animal and human binge eating have similar manifestations, such as overeating in the absence of hunger and preference for highenergy foods, which suggest that they share overlapping

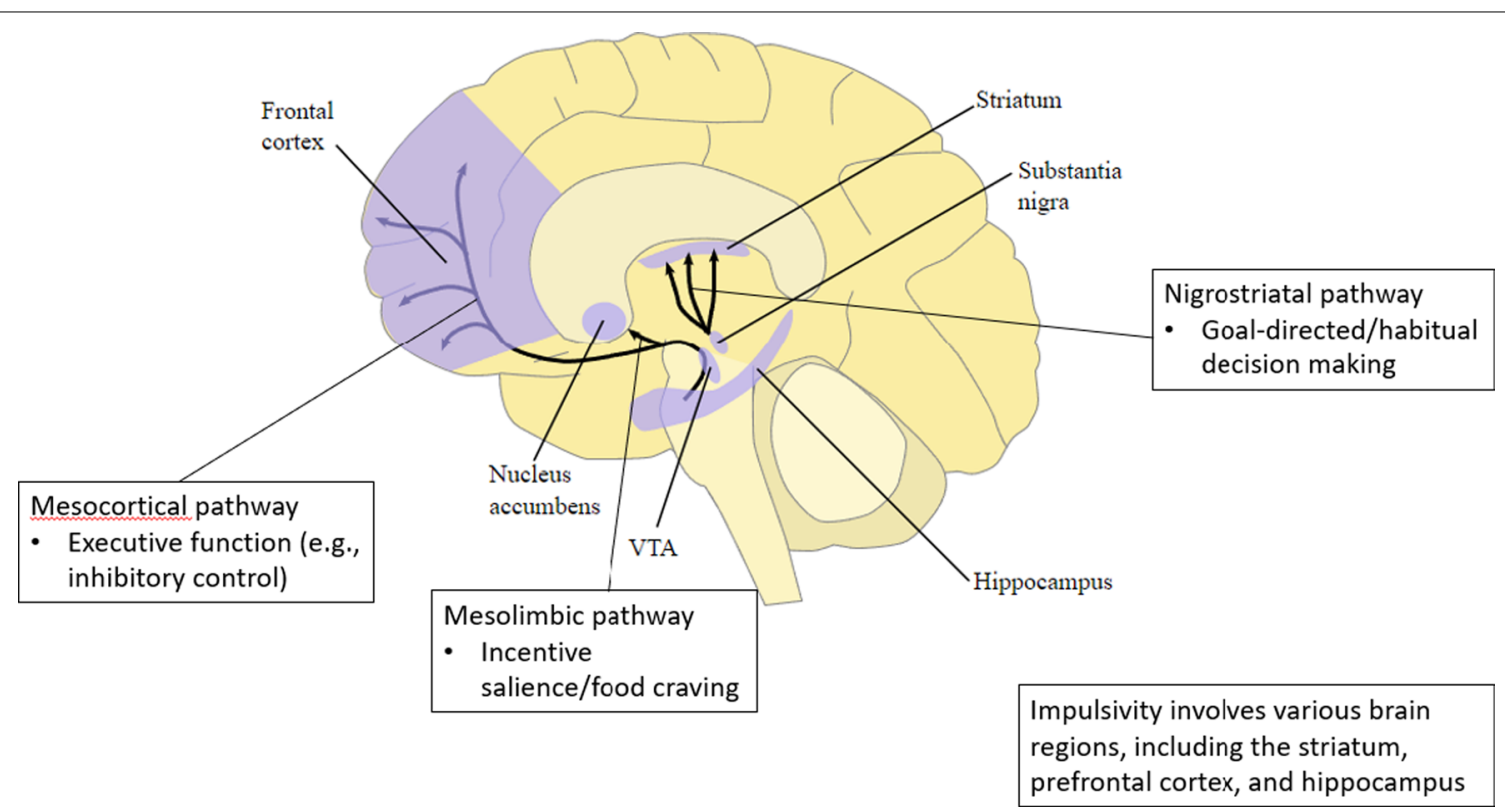

Fig. 1 Dopaminergic pathways and corresponding risk factors of binge eating. * The original figure was developed by the National Institute of Health, and is in the public domain 
biological mechanisms. However, animal models cannot fully replicate the complexity of human binge eating. For example, human binge eating is often triggered by psychological risk factors, while animal binge eating is manipulated by the experimenter. Therefore, despite that animal models represent a valuable tool, human studies are critical to better understand how dopamine contributes to binge eating. Furthermore, although previous reviews generally support dopamine alterations in $\mathrm{BED}$ or $\mathrm{BN}$, the direction of the alterations appears to be mixed. Importantly, none of the reviews has attempted to reconcile the mixed results.

During the past decade, there have been increasing efforts to delineate the role of dopamine in binge eating both in humans and animals. Therefore, the goal of this review is to provide an updated assessment of the literature on binge eating and dopamine, including dopamine levels (synthesis, release), dopamine activities, dopamine regulator (dopamine transporter, degrading enzymes) levels/activities, and dopamine receptor availability/affinity, in both humans and animals.

\section{Methods}

Animal studies were included if (1) they examined binge eating in relation to dopamine levels/activities, dopamine regulator levels/activities, or dopamine receptor availability/affinity, and (2) the binge eating was induced by one of the three standard paradigms: food restriction (periods of food restriction followed by periods of free access to palatable foods), food restriction and stress (periods of food restriction followed by stress exposure), and intermittent access (ad libitum access to standard chow and water, combined with intermittent access to palatable foods).

Human studies were included in this review if they (1) compared dopamine levels/activities, dopamine regulator levels/activities, or dopamine receptor availability/ affinity between adults with binge eating, BED, or BN and healthy controls; or (2) described the associations of dopamine levels/activities, dopamine regulator levels/ activities, or dopamine receptor availability/affinity with binge eating symptoms among healthy or communitybased adults, or adults with binge eating, BED, or BN.

Qualitative studies, abstracts, editorials, case studies, book chapters, dissertation work, and review papers were excluded.

The literature search was conducted in July 2020 with two databases (PubMed and PsycINFO) to obtain relevant studies published since 2010. The search included the combination of the following keywords: "dopamine", "binge eating", and "bulimia". The database search was complemented by a hand search of the reference lists obtained from the identified articles. The study selection flow is presented in Fig. 2.

\section{Results}

\section{Study characteristics}

This review included 25 human studies and six animal studies. Among the 25 human studies, participants had $\operatorname{BED}(n=6), B N(n=7)$, remitted BN $(n=3)$, both BED and $\mathrm{BN}(\mathrm{n}=3)$, and binge eating symptoms $(\mathrm{n}=3)$, and the remaining three studies were comprised of healthy adults or community-based adults. Most of the human studies used case-control design $(\mathrm{n}=12)$, and the others were randomized controlled trials (RCTs, $n=7$ ), crosssectional studies $(\mathrm{n}=5)$, and randomized crossover study $(n=1)$. For the six animal studies, four used male adult rats, and two used female adult rats. The intermittent access paradigm was consistently used to induce binge eating.

\section{Techniques used to measure dopamine levels/activities, dopamine regulator levels/activities, and dopamine receptor availability/affinity Neuroimaging technique}

PET PET relies on the administration and subsequent detection of positron-emitting radiotracers. The radiotracer $\left[{ }^{11} \mathrm{C}\right]$ raclopride has a high selectivity and affinity to the D2 receptor; thus, it competes with endogenous dopamine binding to the $\mathrm{D} 2$ receptor-when endogenous dopamine increases, the radioligand signal decreases [46]. Furthermore, the change of radioligand signal before and after dopamine psychostimulant (e.g., methylphenidate) administration can be used to measure the extracellular dopamine release. Another radiotracer, $\left[{ }^{18} \mathrm{~F}\right]$ fluorodopa, is an analog of a dopamine precursor, which is uptaken by the presynapse and consequently promotes dopamine synthesis. Therefore, PET can accomplish three primary goals: measuring dopamine receptor availability/affinity, measuring the extracellular dopamine release, and measuring the dopamine synthesis capacity. Three studies used PET in this review: two used $\left[{ }^{11} \mathrm{C}\right]$ raclopride in conjunction with methylphenidate to measure dopamine D2 receptor availability/affinity and dopamine release (after methylphenidate) $[47,48]$, and one used $\left[{ }^{18} \mathrm{~F}\right]$ fluorodopa to measure dopamine synthesis capacity [49].

fMRI fMRI measures the hemodynamic and metabolic consequences of brain neuronal activity known as bloodoxygen-level-dependent (BOLD) signal. Although the BOLD signal reflects a mix of neurotransmitter dynamics (e.g., dopamine, acetylcholine, serotonin), many studies have reported a significant relationship between dopamine levels/activities and BOLD signal variability in dopamine-relevant brain regions (e.g., striatum) [50, 51], 


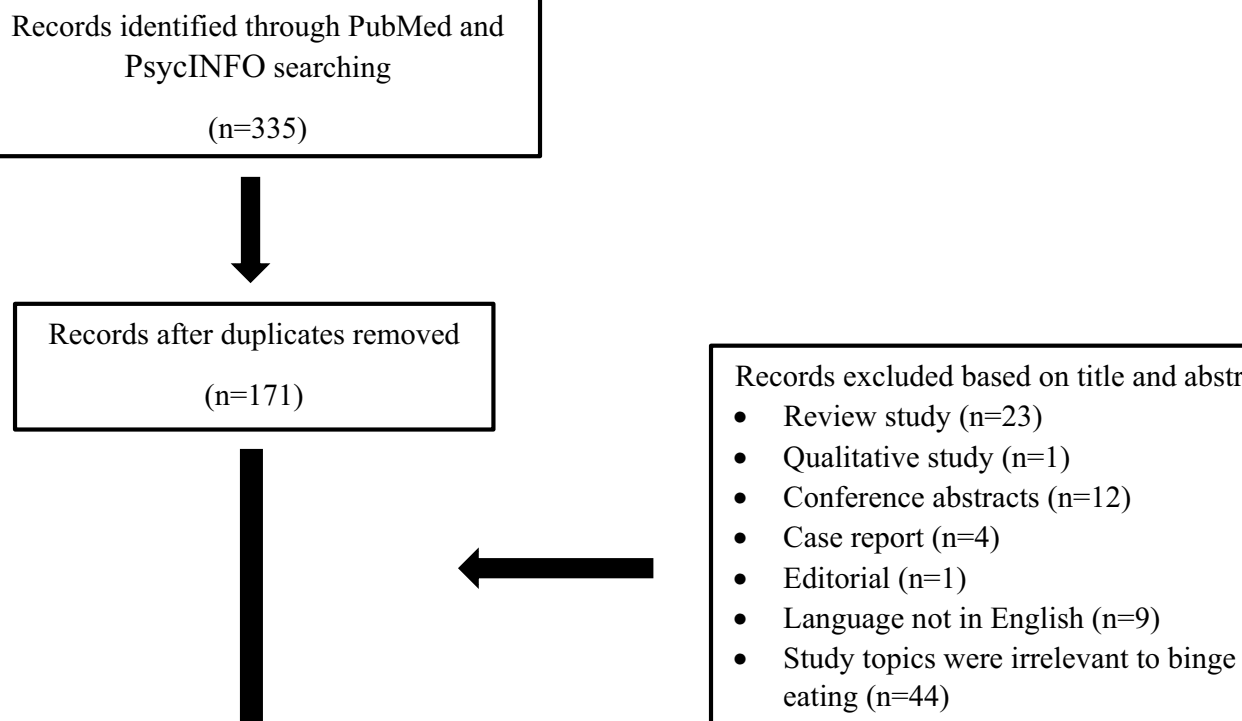

- Review study ( $\mathrm{n}=23)$

- Qualitative study $(\mathrm{n}=1)$

- Conference abstracts $(\mathrm{n}=12)$

- Case report $(n=4)$

- Editorial $(n=1)$

- Language not in English $(n=9)$

- Study topics were irrelevant to binge eating $(n=44)$

Records screened for full-text $(n=77)$

Records excluded based on full text

- Did not report outcome separately for the binge eating group $(n=15)$

- Did not report associations between dopamine and binge eating $(n=31)$

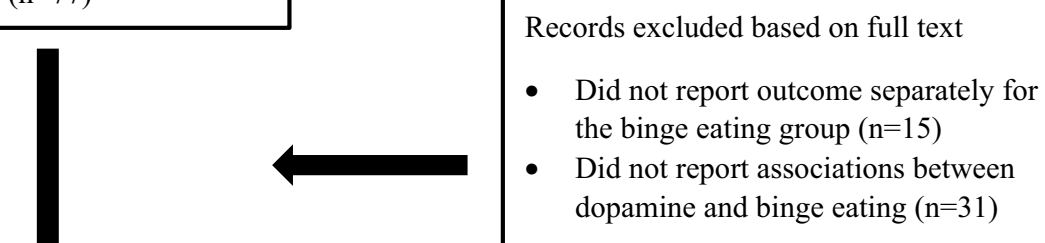

Studies included in the review $(\mathrm{n}=31)$

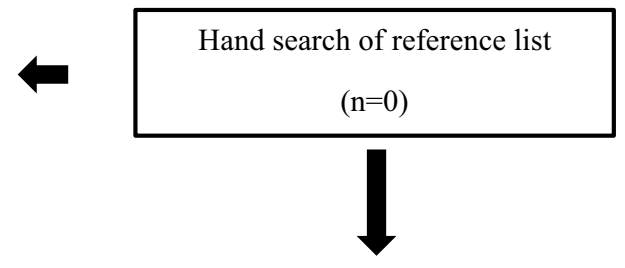

Studies included for final synthesis

$(n=31)$

Fig. 2 Study selection flow

thus supporting its use as an indirect measure of dopamine function. Among the three included fMRI studies, one measured the brain activity in response to taste stimuli, based on a dopamine-related reward learning paradigm, in several brain regions of interest (e.g., ventral putamen, lateral orbitofrontal cortex) [52]. The other two studies measured brain activity to money cues after dopamine depletion [53], or brain activity to food image after applying dopamine D3 antagonist [54]. The application of dopamine-related tasks or drugs in these studies further strengthened the confidence to use the BOLD signal as a robust proxy for dopamine function.

\section{Genetic techniques}

The two primary genetic approaches have been to measure gene expression levels and to look for naturally 
occurring genetic polymorphisms in dopaminergic genes. Three studies [55-57] analyzed mRNA expression for dopamine receptors and dopamine transporter, while the majority of studies examined the genetic polymorphisms coding for dopamine receptor D2 genes [58-61], receptor D3 genes [60], receptor D4 genes [61-63], dopamine transporter genes [59-61], and dopamine degrading enzyme COMT genes $[59,61,64-66]$.

D2 receptor gene Several polymorphisms of the D2 receptor gene have been studied: (1) Taq1A C/T: the T (A1) allele is associated with lower levels of D2 receptor availability and binding affinity relative to the $C$ (A2) allele [67, 68]; (2) C957T: the T/T allele is associated with higher D2 receptor availability and binding affinity compared to C/T and C/C [69]; and (3) - 141 Ins/Del: the DelC minor allele is associated with reduced D2 expression [70].

D3 and D4 receptor genes There are also polymorphisms in the lesser studied D3 and D4 receptors. The Ser9Gly variant is a functional polymorphic site in the D3 receptor gene, which increases the D3 receptor binding affinity for dopamine [71]. The $\mathrm{D} 4$ receptor contains a 48-base pair region that occurs with a variable number of tandem repeats in different individuals. This polymorphism is the most extensively investigated. Compared to the 2-repeat or 4-repeat allele, the 7-repeat (7R) allele decreases D4 receptor availability and binding affinity [72].

Dopamine transporter gene The dopamine transporter gene also has a region with a variable number of tandem repeats, and it is the most studied dopamine transporter polymorphism. Relative to the 10-repeat allele, the 9-repeat allele is associated with lower dopamine transporter expression, resulting in increased synaptic dopamine levels for 9-repeat allele carriers [73].

COMT gene The gene encoding the dopamine degrading enzyme, COMT, contains a well-studied polymorphism (Val/Met) that influences the protein's ability to degrade extracellular dopamine. The Val allele has a $40 \%$ higher enzymatic activity than the Met allele; therefore, carriers of the Val/Val genotype degrade dopamine in the prefrontal cortex more efficiently, resulting in lower synaptic dopamine levels, compared to those with Met/Met or Val/Met genotype [74].

\section{Pharmacological technique}

In pharmacological studies, several drugs including the immediate dopamine precursor L-DOPA [75], dopamine synthesis inhibitor (alpha-methyl-para-tyrosine [53, 76, 77]), dopamine transporter inhibitors (i.e., methylphenidate $[47,48,78]$; lisdexamfetamine $[79,80]$; dasotraline
[81]), dopamine receptor agonists (i.e., D1 agonist SKF 81297 [56]; D2 agonist quinpirole [56]), and dopamine receptor antagonists (i.e., D1 receptor antagonist $\mathrm{SCH}$ 23390 [56, 82]; D2 receptor antagonist raclopride [82, 83]; D3 receptor antagonist GSK598809 [54]) have been used to manipulate the dopamine levels and activities.

\section{Studies that reported a hyperdopaminergic state in binge eating}

The hyperdopaminergic state $(n=9)$ is characterized by (1) two human case-control studies that reported increased dopamine levels and higher dopamine receptor availability/affinity in patients with binge eating than those without binge eating; (2) five cross-sectional studies that showed positive associations of dopamine levels, activities, and receptor availability/affinity with binge eating symptoms among healthy adults, community-based adults, or adults with binge eating; and (3) two animal studies that demonstrated dopamine receptor-blocked or dopamine-depleted rats reduced or failed to develop binge eating symptoms (Table 1 ).

\section{Human case-control studies}

One study [48] applied the PET technique among ten patients with obesity and BED and eight controls with obesity but not BED. PET scanning with $\left[{ }^{11} \mathrm{C}\right]$ raclopride was conducted to measure extracellular dopamine release in response to food or neutral stimulation, after placebo or after oral methylphenidate (a dopamine transporter inhibitor). Results revealed that under the condition of food stimuli and methylphenidate, binge eaters showed significantly more dopamine release in the caudate compared to non-binge eaters, and the increased dopamine release was significantly correlated with higher binge eating severity.

Davis et al. [58] compared five polymorphisms in the dopamine D2 receptor genes (e.g., Taq1A, C957T, and $-141 \mathrm{C}$ ins/del) between 79 adults with obesity and BED and 151 adults with obesity but without BED. The results showed that participants with $B E D$ were more likely to carry the A2/A2 allele of Taq1A and T allele of C957T, which suggested that they had greater D2 receptor availability/affinity compared to the controls without BED.

\section{Human cross-sectional studies}

A research group from Spain analyzed the associations of three polymorphisms in the dopamine genes (D2 receptor: Taq1A; D3 receptor: Ser9Gly; and dopamine transporter: DAT1 variable number of tandem repeats) with binge eating symptoms in patients with BED $(n=34)$ or BN $(n=80)$ [60]. Results revealed that BED patients with the Ser9Gly variant (increases the D3 


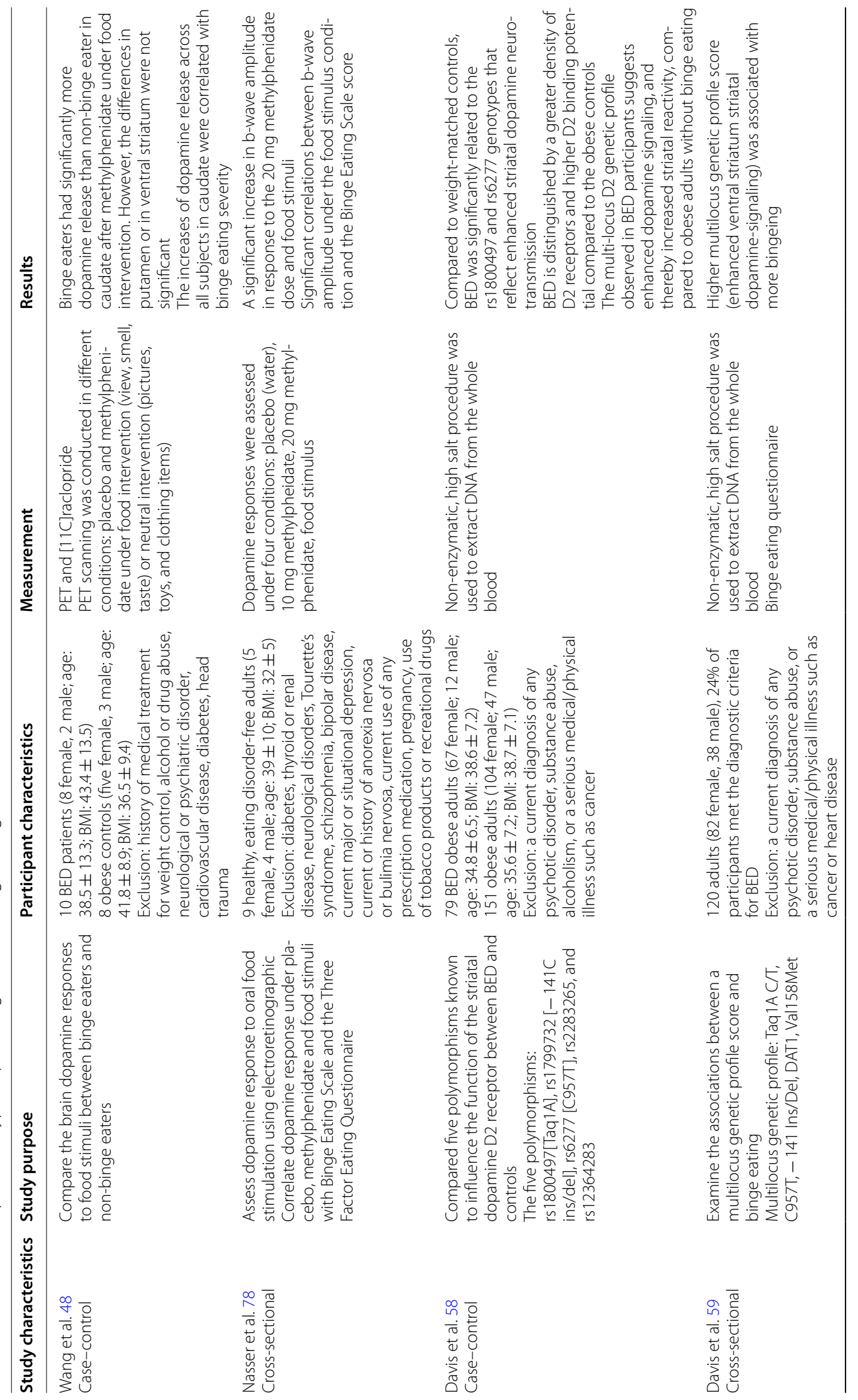




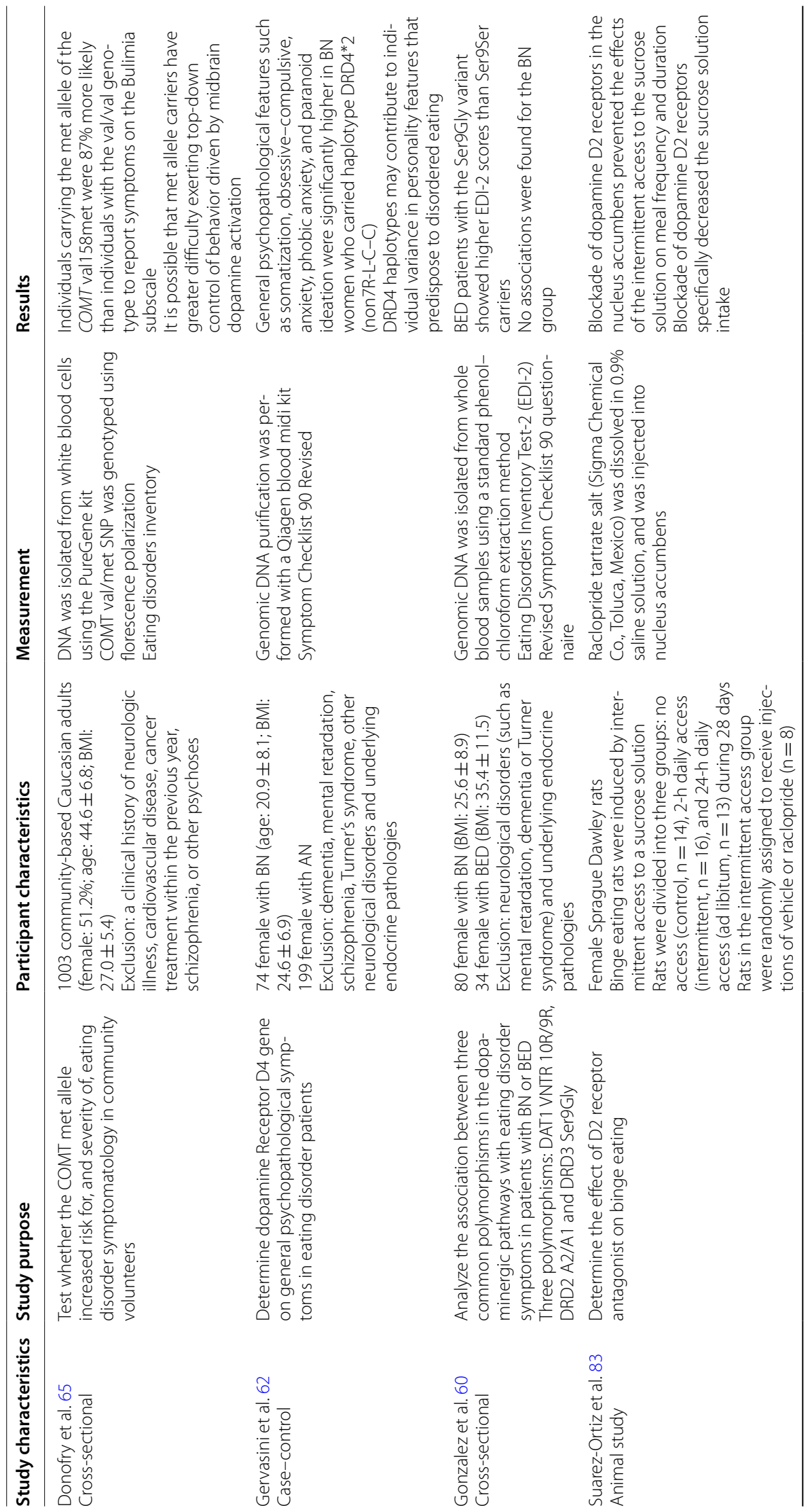




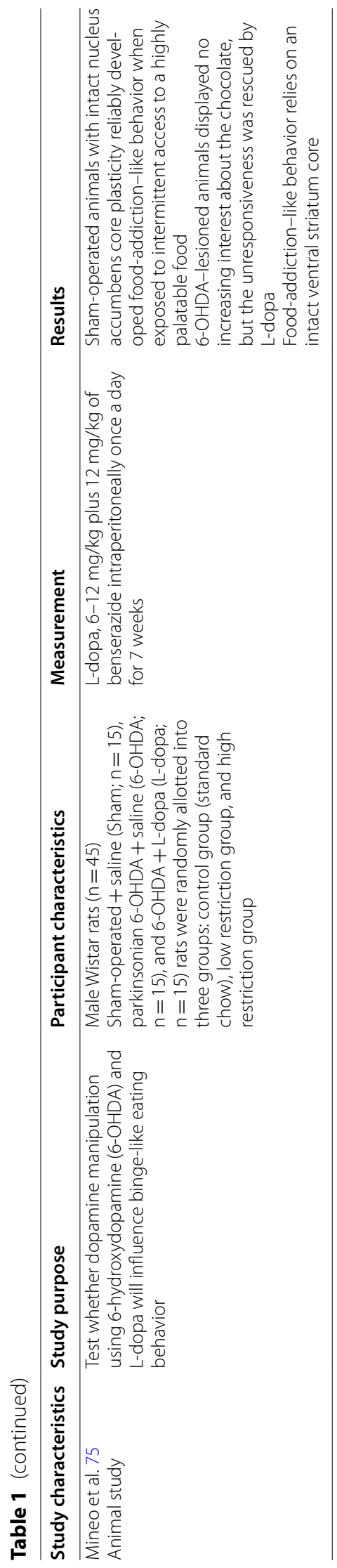


receptor binding affinity for dopamine, $47 \%$ of the group) showed more eating disorder-related psychopathology than BED patients with the Ser9Ser variant. Neither of the polymorphisms in the D2 receptor gene (Taq1A) or dopamine transporter gene (DAT1) was associated with symptom severity in the BED group.

In a study with $74 \mathrm{BN}$ patients [62], the authors examined the dopamine D4 receptor polymorphism, a 48-base pair region with a variable number of tandem repeats (alleles are denoted $7 R$ and non-7R, the $7 R$ allele decreases $\mathrm{D} 4$ receptor availability and binding affinity). They found that $77 \%$ of BN patients carried non-7R/non$7 \mathrm{R}$ alleles. In contrast, only $4.1 \%$ of $\mathrm{BN}$ patients carried the $7 R / 7 R$ allele. Furthermore, carriers of a combination of the non-7R/non-7R with other $\mathrm{D} 4$ receptor alleles that confer personality traits that are risk factors for binge eating (e.g., attention deficit, borderline personality), experienced more severe general psychopathology compared to non-carriers.

In a study of 1003 community-based adults [65], the authors examined the associations between COMT gene polymorphisms and the likelihood of binge eating symptoms. They found that individuals carrying the Met allele of the COMT gene (lower activity allele) were at a higher risk for binge symptoms compared with Val/Val allele carriers.

Davis et al. [59] examined whether a multilocus genetic profile score based on six dopamine-related polymorphisms (e.g., D2 receptor: Taq1A; dopamine transporter: DAT1 variable number of tandem repeats; COMT: Val158Met) was associated with binge eating symptoms in 120 adults. Results showed that a higher multilocus genetic profile score, which reflected higher striatal dopamine signaling, was linked to more binge eating behaviors.

A small-scale study [78] of eight adults with obesity (but without a diagnosed eating disorder) used electroretinography to estimate brain dopamine activity after oral food stimuli. The authors found that the cone electroretinography response significantly increased to food stimuli, and the increased response was positively associated with binge eating symptoms.

\section{Animal studies}

An animal study [75] used male rats that were either dopamine-depleted $(n=30)$ or dopamine-intact $(n=15)$, and the dopamine-depleted rats were further randomized into the saline group $(\mathrm{n}=15)$ and L-DOPA group $(n=15)$. With the intermittent access paradigm, the rats in the dopamine-intact and dopamine-depleted with L-DOPA groups developed binge eating behaviors; however, the rats in the dopamine-depleted with saline were non-responsive to the procedure. This result led to the conclusion that intact dopamine is necessary for driving binge eating behaviors.

Another animal study [83] used female rats to evaluate whether inhibiting D2 receptors by injecting the antagonist, raclopride, in the nucleus accumbens reduced binge eating behaviors in binge-eating rats. With the intermittent access paradigm, the rats who developed binge eating $(n=16)$ were given an injection of raclopride $(n=8)$ or vehicle $(n=8)$. Results showed that rats with intranucleus accumbens raclopride injection demonstrated reduced meal frequency, meal duration, and sucrose solution intake compared to those with vehicle injection. Thus, the availability of dopamine D2 receptors in the ventral striatum is necessary to maintain binge eating behaviors in female rats.

\section{Studies that reported hypodopaminergic state in binge eating}

The hypodopaminergic state $(n=17)$ is characterized by 1) six case-control studies that reported decreased dopamine levels, reduced dopamine activities, and lower dopamine receptor availability/affinity in patients with binge eating compared to those without binge eating; 2 ) two cross-sectional studies that showed negative associations between dopamine levels and binge eating symptoms in patients with $\mathrm{BN}$ or BED; 3) six RCTs and one randomized crossover study that reported using dopamine synthesis inhibitor triggered binge eating, or using dopamine transported inhibitor reduced binge eating; and 4) two animal studies that demonstrated lower dopamine receptor levels/affinity in binge rats (Table 2).

\section{Human case-control studies}

Frank et al. [52] used fMRI to examine the brain activity in 20 females with $\mathrm{BN}$ and 23 healthy controls in a temporal difference model during which participants learned to associate three unconditioned taste stimuli to a paired conditioned visual stimulus. In healthy subjects, it is expected that dopamine levels will increase in response to unexpected unconditioned stimuli, and dopamine levels will decrease if the conditioned stimuli are followed by an omission of the unconditioned stimuli. Results showed that BN individuals had a blunted BOLD response (a proxy of dopamine function) to both unexpected unconditioned stimuli and omission of unconditioned stimuli in several brain areas (e.g., ventral putamen, orbitofrontal cortex) compared to controls. Furthermore, the reduced response was significantly correlated to binge/purge frequency.

A small-scale study [49] used PET scanning with $\left[{ }^{18} \mathrm{~F}\right]$ fluorodopa to compare striatal dopamine synthesis in seven adults with binge eating and obesity and 17 healthy-weight controls. Results revealed a $20 \%$ lower 


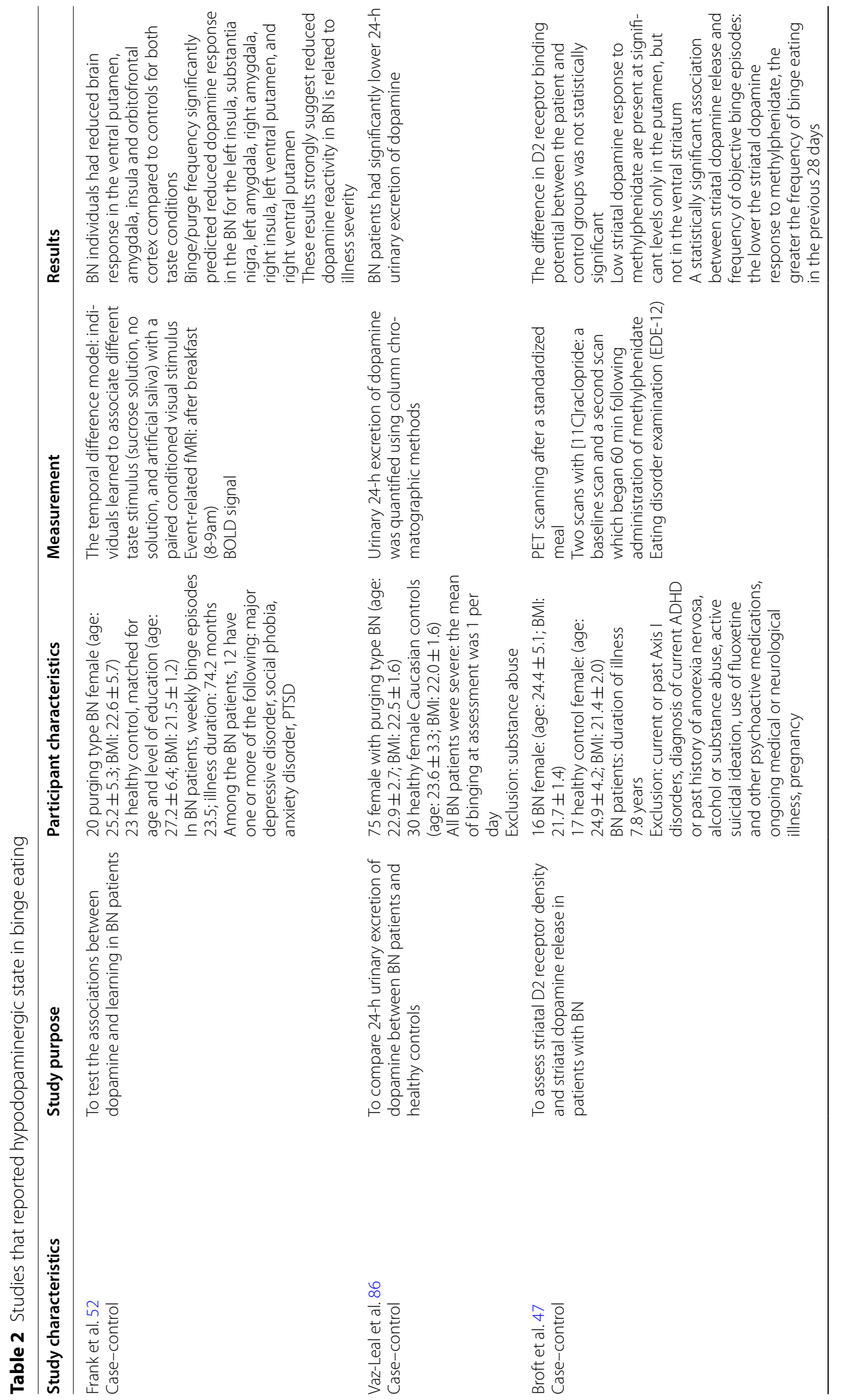




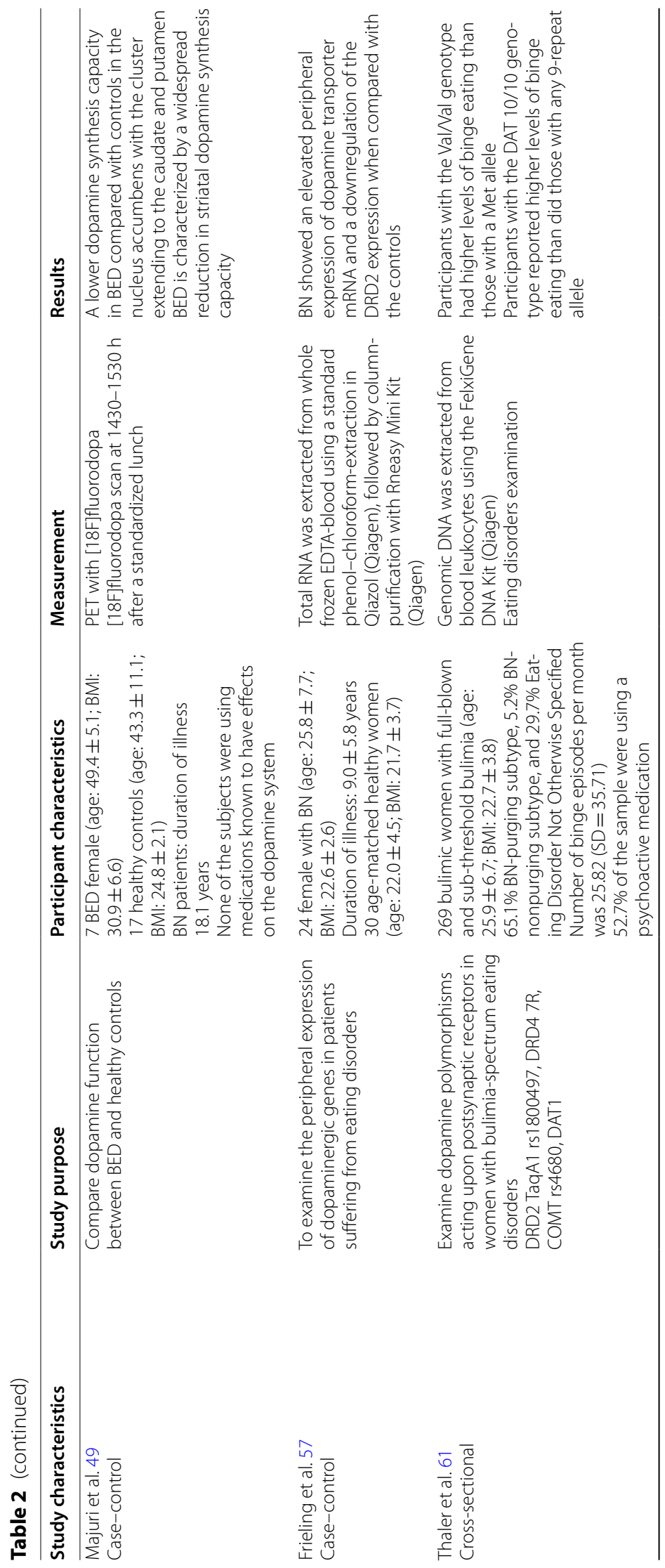




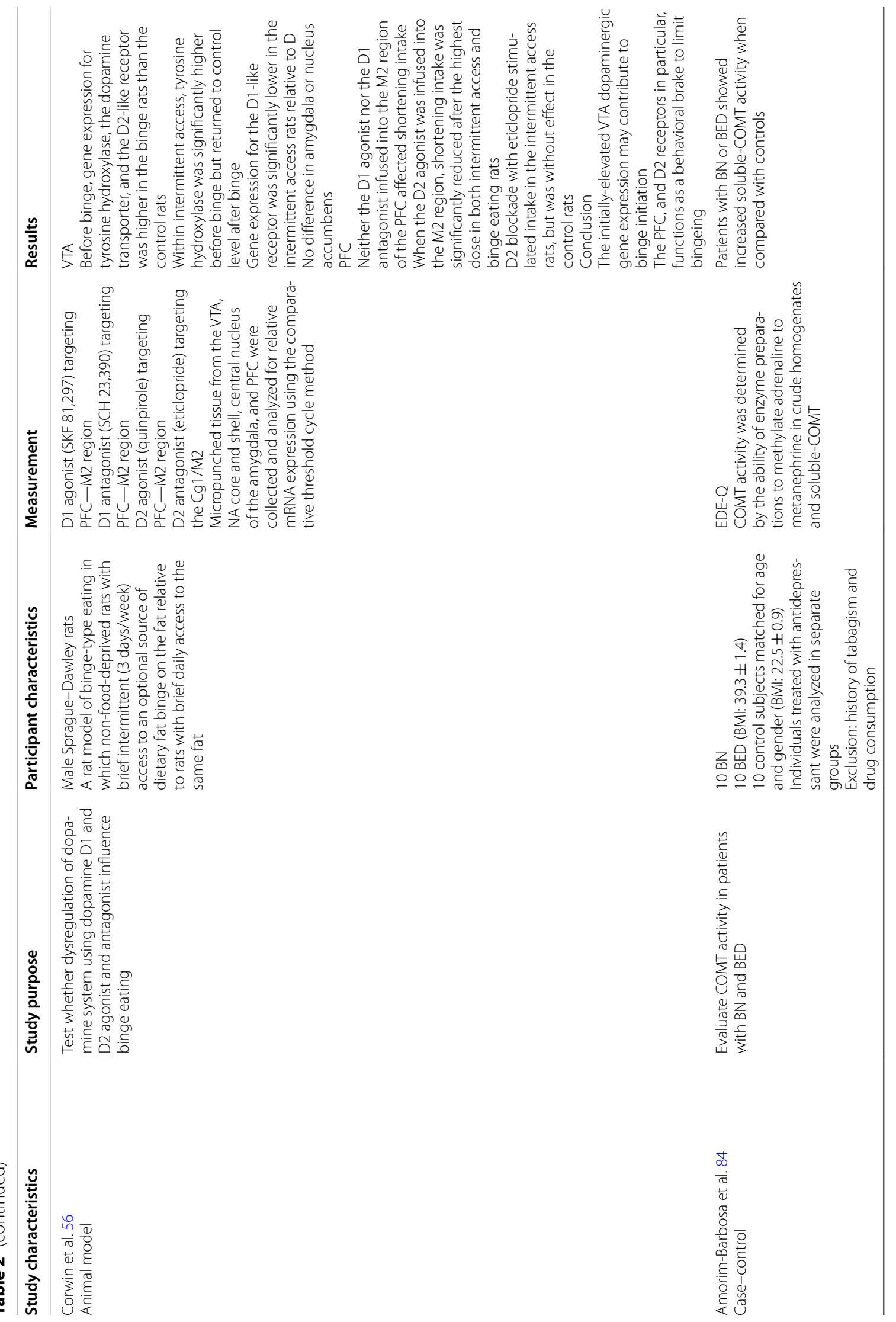




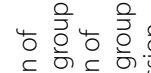

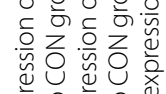

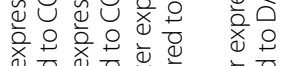

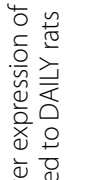

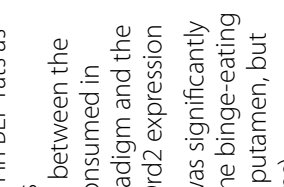

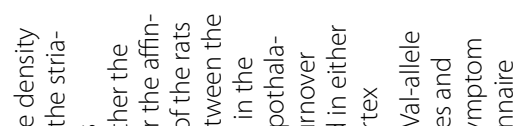

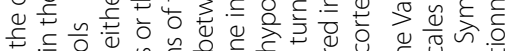

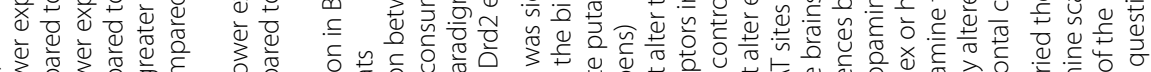

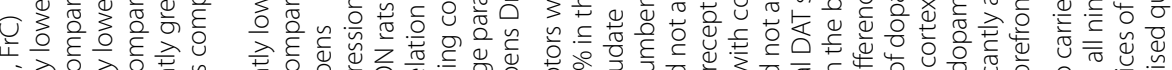

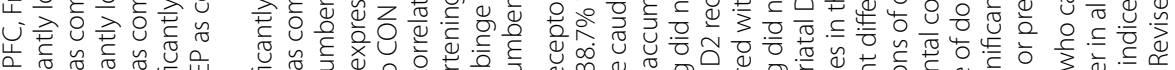

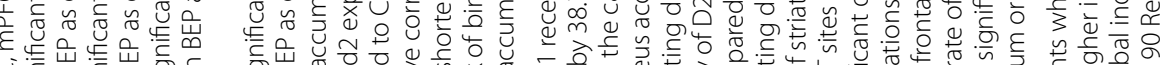

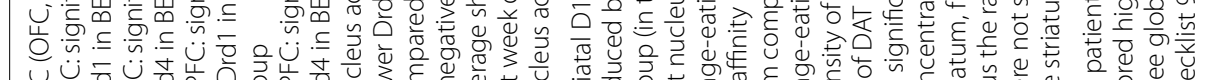

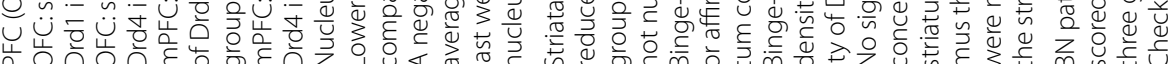

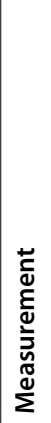

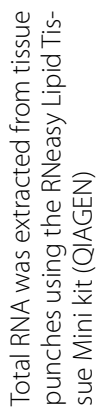

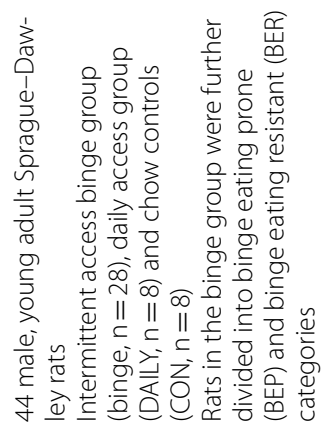

$\frac{\pi}{2}$

눙

을 훙

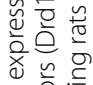

×

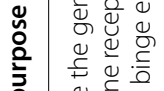

员

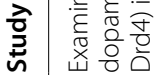
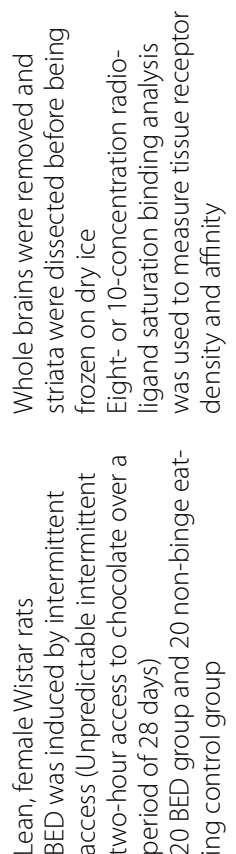

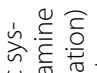

䒛

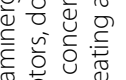

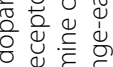

舵

䏠 웅

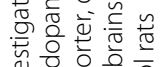

送

只论

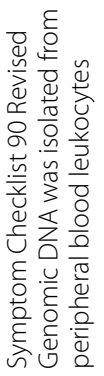
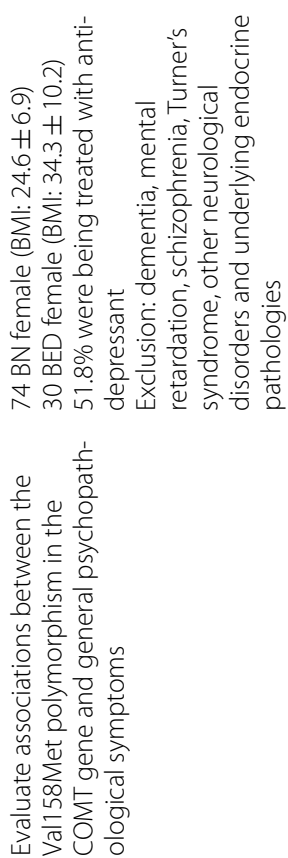


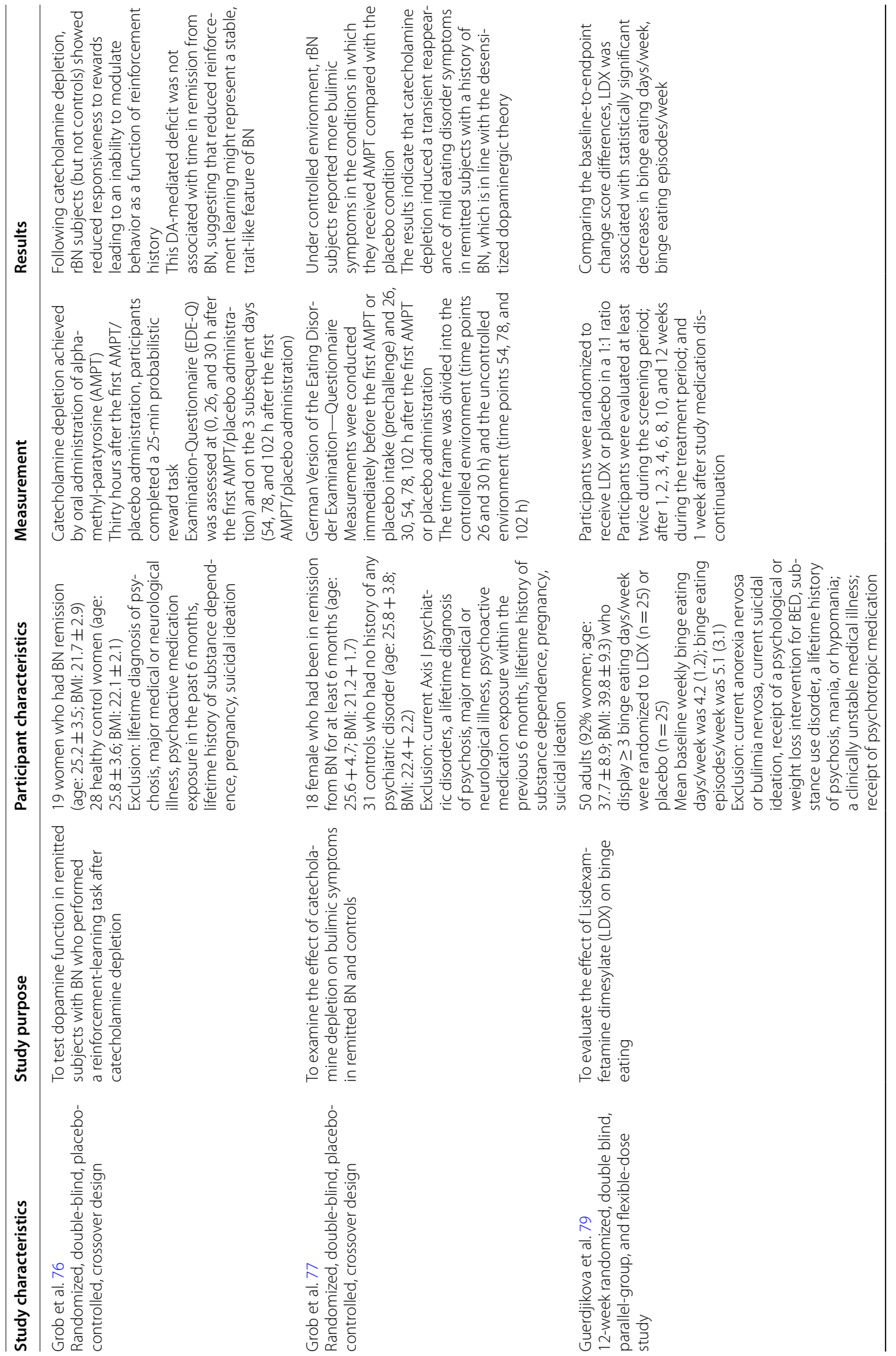




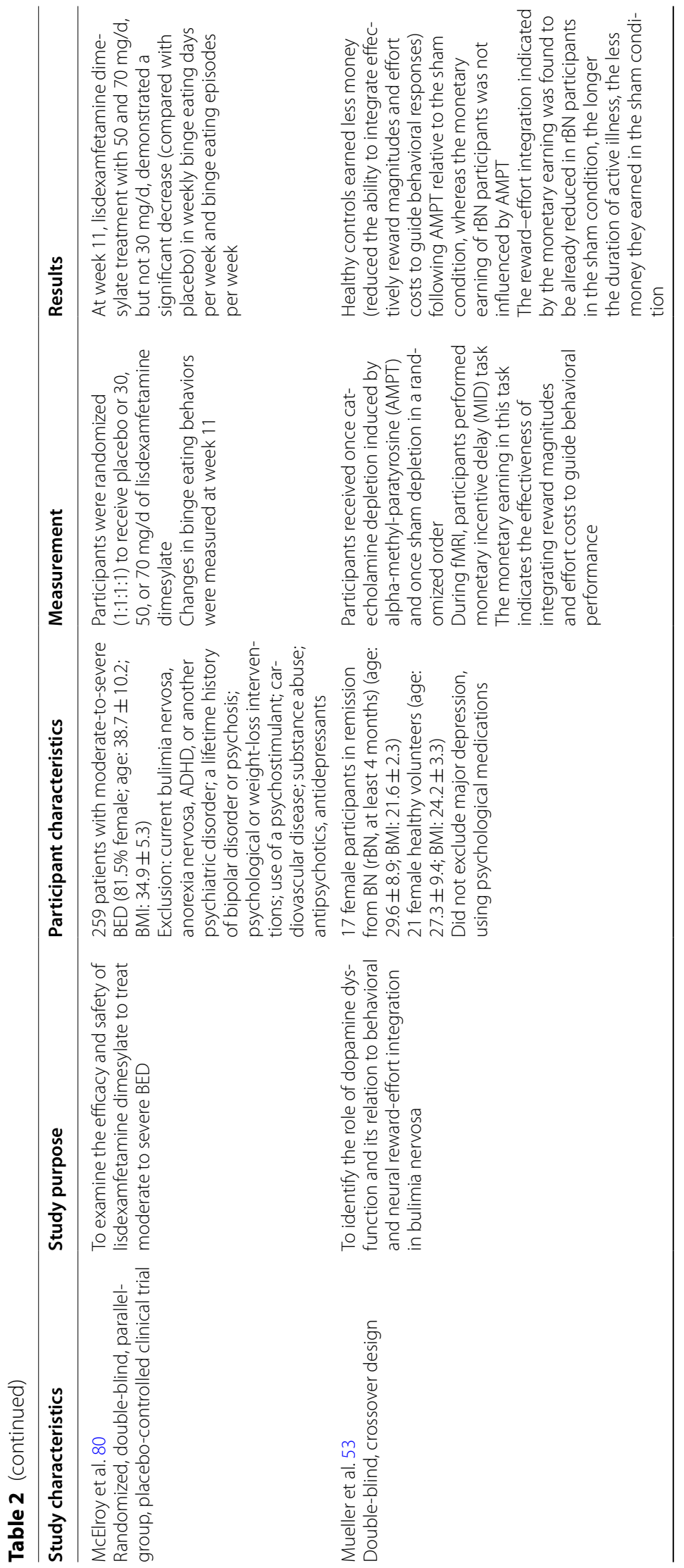




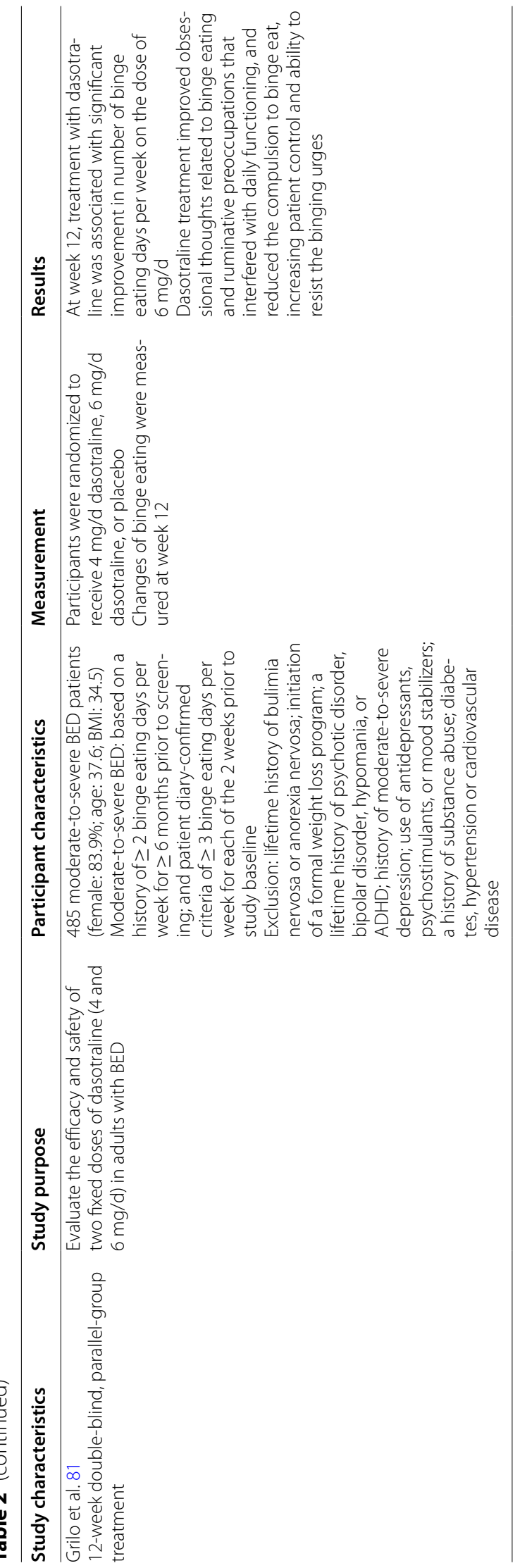


dopamine synthesis capacity in the nucleus accumbens in the BED group compared to the control group.

Another study [47] conducted PET scanning with $\left[{ }^{11} \mathrm{C}\right]$ raclopride among $16 \mathrm{BN}$ patients and 17 healthy controls. The authors found that the BN group had a blunted dopamine release to methylphenidate in the putamen, and the blunted release was correlated to a greater frequency of binge eating in the previous 28 days.

Frieling et al. [57] compared the peripheral expression, which is believed to be somewhat reflective of brain status, of dopamine D2 receptor, dopamine D4 receptor, and dopamine transporter genes in 24 patients with $\mathrm{BN}$ and 30 healthy controls. This study reported a downregulated mRNA expression of the D2 receptor gene and an elevated mRNA expression of dopamine transporter (which would result in less dopamine being available in synapses) in the $\mathrm{BN}$ group compared to controls.

One study analyzed the soluble COMT in erythrocytes with ten BN, ten BED, and ten controls [84]. Soluble COMT is an isoform of COMT that is highly expressed in peripheral tissues, and its activity is encoded for the COMT gene. This study found that participants with $\mathrm{BED}$ or BN had significantly higher soluble COMT activity compared to controls, which collaborate other studies that reported high-activity allele of COMT (Val-allele) in binge eating.

Another study also used peripheral levels of dopamine to infer its central activities. This study compared the urinary levels of dopamine between 75 female patients with purging $\mathrm{BN}$ and 30 healthy controls [86], and found lower 24-h excretion of dopamine in patients with $\mathrm{BN}$.

\section{Human cross-sectional studies}

Thaler et al. [61] examined the relationship between the polymorphisms of dopamine-regulating genes (dopamine transporter, COMT) and binge eating among 269 women with spectrum-bulimia disorder. The authors found a positive relationship between dopamine transporter 10-repeat allele (associated with higher dopamine transporter expression) and higher levels of binge eating, and that women with a COMT Val/Val genotype (degrades dopamine at a faster rate, resulting in lower dopamine levels) had higher levels of binge eating than did those with a Met/Met genotype.

Likewise, a cross-sectional study [64] of 303 patients with eating disorders (199 with AN, 74 with BN, and 30 with BED) found that $\mathrm{BN}$ patients who carried the Valallele of COMT gene had more severe psychopathology compared to $\mathrm{BN}$ patients who carried the Met allele, although no such association was found for the BED patients.

\section{Human RCTs and randomized crossover study}

A clinical trial [77] randomized 18 women with remitted $\mathrm{BN}$ and 31 control women to receive alphamethyl-para-tyrosine (a dopamine synthesis inhibitor) or placebo for at least seven days. Results showed that subjects with remitted BN reported more bulimic symptoms in the alpha-methyl-para-tyrosine condition compared with the placebo condition. Two other studies $[53,76]$ from the same research group further demonstrated that subjects with remitted BN had blunted reward responsiveness not only after [76] but also before administration of alpha-methyl-para-tyrosine [53], suggesting a hypodopaminergic state in remitted $\mathrm{BN}$ patients.

McElroy et al. [80] conducted a multi-site study to test the efficacy of lisdexamfetamine dimesylate (a dopamine transporter inhibitor) to treat moderate-to-severe BED. Participants were randomized to receive placebo $(n=63)$ or $30 \mathrm{mg} / \mathrm{d}(\mathrm{n}=66), 50 \mathrm{mg} / \mathrm{d}(\mathrm{n}=65)$, or $70 \mathrm{mg} / \mathrm{d}(\mathrm{n}=66)$ of lisdexamfetamine dimesylate. Results showed that at Week 11, participants treated with 50 and $70 \mathrm{mg} / \mathrm{d}$ lisdexamfetamine dimesylate demonstrated a significant decrease in weekly binge eating frequency compared to the control group. The results were replicated in another RCT [79], which showed significant decreases in binge eating frequency among adults with obesity and binge eating who received lisdexamfetamine dimesylate treatment compared to the placebo group at one week after drug termination.

A 12-week RCT [81] evaluated the effect of dasotraline, a less specific serotonin-norepinephrine-dopamine transporter inhibitor, in the treatment of BED. Patients $(\mathrm{n}=491)$ who displayed moderate-to-severe BED were randomized to a $4 \mathrm{mg} / \mathrm{d}$ dasotraline group, a $6 \mathrm{mg} / \mathrm{d}$ dasotraline group, and a placebo group. Results revealed that treatment with $6 \mathrm{mg} / \mathrm{d}$ dasotraline significantly reduced weekly binge eating frequency and improved BED-related symptoms at week 12 .

\section{Animal studies}

One animal study [55] divided 44 male rats into three groups: intermittent access binge group $(n=28)$, daily access group $(n=8)$, and chow controls $(n=8)$. The rats in the binge group were further classified into binge eating prone $(\mathrm{n}=8)$, binge eating neutral $(\mathrm{n}=12)$, and binge eating resistant $(n=8)$ groups. Authors found lower D1, D2, and D4 receptor mRNA expression in several brain areas (e.g., nucleus accumbens, orbitofrontal cortex) in binge eating prone rats compared to control rats. Additionally, there was a negative correlation between the D2 mRNA expression in nucleus accumbens and food consumed in the binge rats. 
Corwin et al. [56] tested whether activating or inhibiting D1 and D2 receptors in the prefrontal cortex altered the binge eating behaviors of rats. Binge eating was achieved by intermittent access to high-fat shortening, and the authors found that although neither the injection of D1 agonist nor the D1 antagonist into the prefrontal cortex affected shortening intake, the D2 agonist and D2 antagonist significantly reduced and stimulated intake in binge-eating rats, respectively.

\section{Studies that reported unchanged dopaminergic state in binge eating}

The unchanged dopaminergic state $(\mathrm{n}=5)$ is characterized by 1) three case-control studies that reported no difference of dopamine receptor availability/affinity in patients with binge eating compared to those without binge eating; 2) an RCT that showed no effect of dopamine receptor antagonist on binge behaviors; and 3) an animal study that demonstrated no effect of dopamine receptor agonist or antagonist on binge behaviors (Table 3).

\section{Human case-control studies}

In one study that included 206 women with a full threshold or subthreshold BN and 102 healthy controls [85], the authors analyzed the methylation (an epigenetic modification that can impact gene transcription and expression) of the dopamine D2 receptor gene, but found no difference between the two groups. However, it is worth mentioning that 45 of the participants in this study had bipolar disorder or childhood abuse, and the D2 receptor DNA methylation was significantly higher in those participants compared to those without bipolar disorder or childhood abuse.

In another case-control study of 240 females with BN and 240 controls, the authors did not find any difference between $\mathrm{BN}$ patients and controls in terms of $\mathrm{D} 4$ receptor gene polymorphisms [63] or COMT allele frequencies [66]. However, a subgroup of BN patients had a history of attention deficit hyperactivity disorder, which could bias the results.

\section{Human RCTs}

In an RCT [54] with 26 overweight and obese participants who reported binge eating behaviors, the participants were given either a dopamine D3 receptor antagonist or placebo and were exposed to high-fat and general food images. However, fMRI results showed that brain activation (e.g., ventral striatum, caudate, putamen) to food images was not modulated by the D3 receptor antagonist. Additionally, the D3 receptor antagonist had no effect on self-reported eating behaviors.

\section{Animal studies}

An animal study [82] did not find any effect of injecting dopamine D1 (SCH23390) or D2 receptor antagonists (raclopride) into the accumbens on food consumption in male rats with or without a history of intermittent binge access to palatable foods.

\section{Discussion}

This study reviewed the role of dopamine, including dopamine levels, dopamine activities, dopamine regulator levels/activities, and dopamine receptor availability/ affinity, in relation to binge eating among both humans and animals. The primary finding is that the majority of studies $(26 / 31,83.9 \%)$ documented an altered dopaminergic state related to binge eating. However, the literature is inconsistent concerning the direction of the alteration, supporting either a hyperdopaminergic $(9 / 26,34.6 \%)$ or a hypodopaminergic $(17 / 26,65.4 \%)$ state in binge eating.

The dissonance may be partially due to the complexity of the dopamine system (e.g., bursting vs. phasic release) [86] and the variability in sample characteristics (e.g., weight status, age, race), study design, diagnosis criteria, and neuroimaging/genetic/pharmacological techniques, making the interpretations of study findings less straightforward. Additionally, the potential confounders that may influence the reward system and dopamine function (e.g., psychiatric diseases, medications, history of dietary restraint, hunger/satiety) may also contribute to the heterogeneity. In this review, although most studies excluded individuals with psychiatric diseases (e.g., major depression symptoms, post-traumatic stress disorder) and people who had a history of childhood abuse, other studies included these individuals [52, 61, 63, 66, 85]. Because individuals with depression and post-traumatic stress disorder usually have diminished dopamine function [87, 88], and those with childhood abuse usually have elevated dopamine function [89], the inclusion of people with these comorbidities may bias the results.

Another reason that can possibly explain the inconsistency is that this review included two distinct types of eating disorders: BED and BN. Although both BED and $\mathrm{BN}$ are marked by binge eating symptoms, BN additionally requires using compensatory behaviors after binge episodes (e.g., vomiting, using laxatives). Notably, the few studies that have compared the etiology and neural underpinnings of BED and BN revealed that despite a large magnitude of overlap [90], differences exist in the severity of dopamine-related risk factors. For example, patients with BED have been shown to have higher reward sensitivity and less intense top-down control to inhibit the increased food craving than those with BN [91, 92], suggesting the possibility that dopamine 


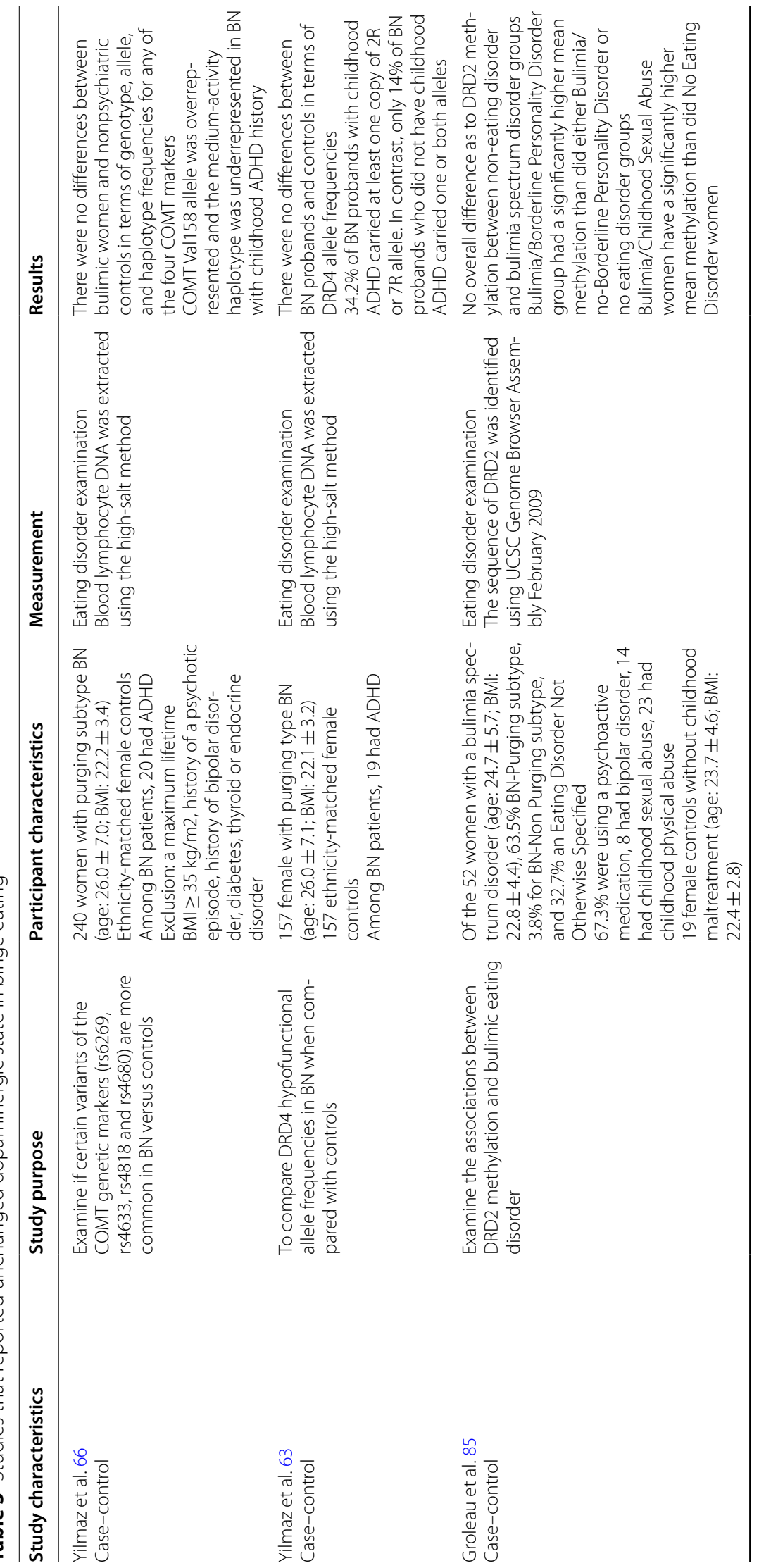




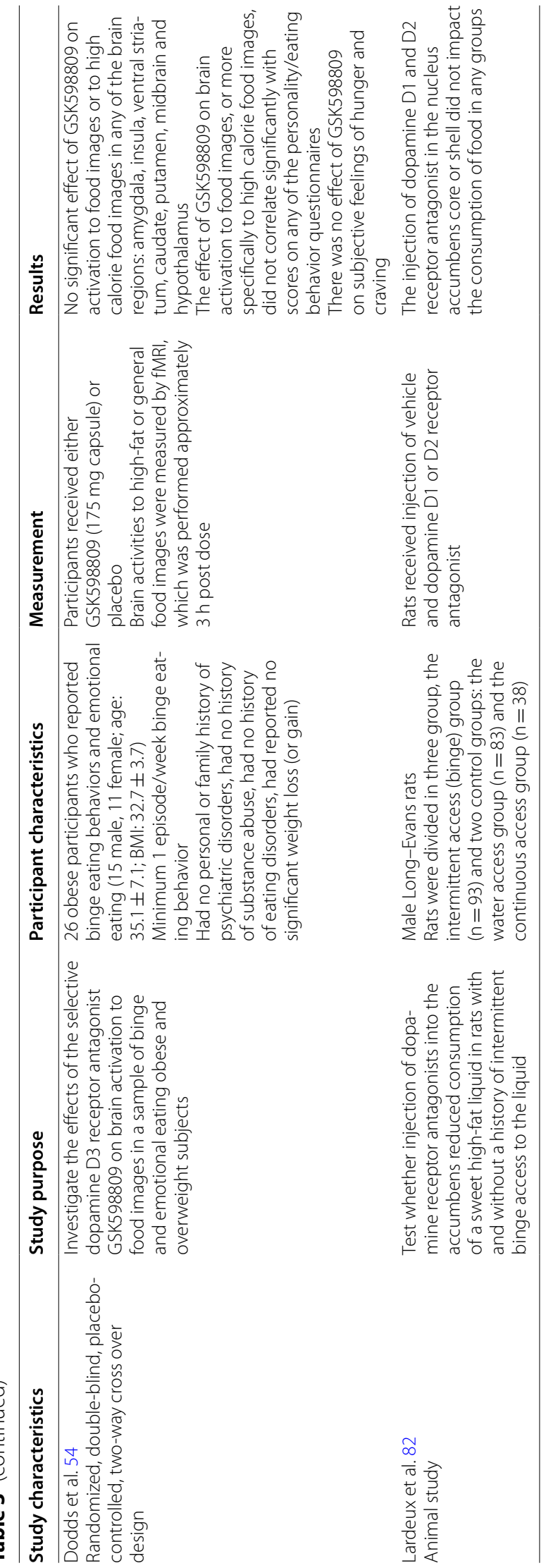


may function differently in BED and BN. In this review, among the eight studies that reported an altered dopaminergic state in the BED population, one half of the studies supported the hyperdopaminergic state and the other half supported a hypodopaminergic state but with a stronger level of evidence from RCTs. A more consistent trend was observed in the BN population with nine out of ten studies supporting a hypodopaminergic state, suggesting that dopamine may be downregulated in this specific eating disorder. Future studies may benefit from directly comparing the dopamine function among BED, $\mathrm{BN}$, and preferably purging-only groups to better understand how dopamine contributes to binge-related eating disorders.

Although there are possible explanations for the inconsistent findings, two hypotheses that could potentially reconcile the inconsistency should be considered in future studies. The first hypothesis is that instead of being mutually exclusive, the hyperdopaminergic and hypodopaminergic states may co-exist, but in different stages of binge eating. This hypothesis is supported by the observations in this review as well as similar conjectures proposed in other disease conditions that are highly correlated with binge eating, such as obesity and substance use disorder.

Among studies included in this review, although not all of them reported the stage or severity of binge eating, the two studies $[59,78]$ conducted among community-based adults who were completely or partially free of diagnosed binge eating supported a positive association between dopamine activity and binge eating symptoms. In contrast, eight studies $[47,49,52,57,61,79-81$, 93] that included participants with moderate-to-severe binge eating or participants with a long illness duration (three being RCTs) supported a hypodopaminergic state in binge eaters. Plus, the three studies that documented a desensitized dopamine system in remitted BN patients $[53,76,77]$ provided further evidence of a hypodopaminergic state in the late stages of binge eating. These results suggest that dopamine elevations may contribute to the initiation of binge eating, but a downregulation may occur after repeated bingeing, which perpetuates the behavior. Notably, while no human study has longitudinally examined dopamine function over the course of binge eating, one animal study has investigated the overall neural activation in the nucleus accumbens among female rats in early- and chronic- stages of binge eating [94]. The study results suggested a hyper-neural activation to reward in the early stages of binge eating and a decreased activation in the later stages of binge eating [94].

The hypothesis of hyper- then hypodopaminergic state in binge eating is also consistent with the reward-related models or theories in obesity (dynamic vulnerability model), drug addiction (dopamine desensitization theory), and alcohol use disorder (three-stage model). In obesity literature, two opposing dopamine-related theories are debated-the reward surfeit and reward deficit theories [95]. The former posits that greater reward responsivity (greater dopamine signaling) to high-energy foods increases the risk for obesity, while the latter proposes the opposite [96, 97]. Stice et al. [96] reviewed prospective studies that examined predictors of weight gain and found convergent evidence supporting an association between greater reward responsivity to high-calorie foods and increased risk for future weight gain. On the contrary, there was little evidence supporting such association for decreased reward responsivity. Therefore, hypo-responsivity of reward is likely to represent the consequence rather than a precursor of weight gain [96].

Binge eating is also highly correlated with substance use disorder as the two disease conditions have a high comorbidity (e.g., binge eaters are more likely to use alcohol and illicit drug compared to controls) $[98,99]$ and share common symptomatology (e.g., an overwhelming desire for food/substances, a feeling of "loss of control" even in the face of adverse consequences, and preoccupation with thoughts of food/substances) [100], risk factors (e.g., increased reward sensitivity, impulsivity, and diminished self-control), and neurobiological underpinnings (e.g., interruptions in the dopaminergic pathways) [99, 100]. Therefore, the dopamine-related theories of substance use disorder may also apply to binge eating.

The dopamine desensitization theory of drug addiction proposes that dopamine elevations occur in the initial stages of addiction but not after repeated excessive intake of drugs. Instead, the later stage of drug use is possibly associated with a decreased dopamine release, reduced dopamine D2 receptor availability, and downregulated dopaminergic responses to drug cues [101-103]. Likewise, the three-stage model (binge/intoxication, withdrawal/negative affect, and preoccupation/anticipation) of alcohol dependence proposes that the binge/intoxication stage, which is characterized by positive reinforcement processes and is dependent on dopamine release in the right ventral striatum, lays the groundwork for initial transition to addiction. Following chronic alcohol exposure, the subsequent withdrawal/negative affect stage is associated with compromised dopamine functions that contribute to the decreased sensitivity to rewards and alcohol tolerance [104, 105].

An alternate hypothesis to reconcile the inconsistent findings is that the hyper- and hypodopaminergic states represent two distinct pathways to binge eating, and individual genotypes determine whether it is the hyperor hypodopaminergic state that confers a risk of binge 
eating [106]. This hypothesis was initially proposed in the obesity research, and two studies from this review appeared to provide support for distinct pathways.

As previously mentioned, both reward surfeit and reward deficit theories exist to explain the development of obesity. Despite that evidence overwhelmingly supported the reward surfeit theory, Stice et al. [97] tested whether the Taq1A (dopamine D2 receptor gene) polymorphism moderated the relationship between reward responsivity and body fat gain. The authors conducted a food reward fMRI paradigm with milkshake as a stimulus among 153 adolescents, and found that elevated caudate response to milkshake receipt predicted body fat gain for youth with a genetic propensity for the Taq1A A2/A2 allele (higher levels of D2 receptor availability and binding affinity), but lower caudate response predicted body fat gain for youth with a genetic propensity for the Taq1A A1 allele over a 3-year follow-up [97]. This finding suggested that there were distinguishable subtypes of obesity that can be predicted by dopamine genotypes.

In this review, two studies have compared the Taq1A $\mathrm{A} 1$ and A2 allele between BED patients and healthy controls, with one study reporting overrepresentation of Taq1A A1 [58] and the other reporting overrepresentation of Taq1A A2 allele [60] in the BED group. This inconsistency could be potentially solved by the possibility that both hyperdopaminergic and hypodopaminergic state predicts binge eating, but in individuals with a genetic predisposition to higher and lower dopamine signaling, respectively. However, this hypothetical interaction between individual genotype and dopamine function should be directly examined in future binge eating studies.

This review has several limitations. First, results were organized based on different dopaminergic states in binge eating behaviors. While this structure makes the opposing viewpoints stand out and emphasizes the possibility of the co-existence of hyper- and hypodopaminergic states in binge eating, it may complicate the direct comparisons between studies that used the same technique (e.g., neuroimaging, genetic) or adopted a similar study design (e.g., case-control, RCT). Additional limitations are mostly limitations that are inherent in the included studies, including small sample size, lack of control for confounding variables in some studies, and the absence of longitudinal studies that cover different stages of binge eating (e.g., onset, maintenance, remission). Moreover, it should be noticed that only a few studies reported the specific brain areas where dopamine alterations occur, and no study functionally correlated the alterations to corresponding risk factors of binge eating. This limitation precludes a clear understanding of what aberrant dopamine functions contribute to the initiation or maintenance of binge eating. Studies from substance use disorder have provided useful clues for the delineation of specific brain areas and dopamine functions in different disease stages. For example, the three-stage model of alcohol dependence elaborates that the three stages-binge/intoxication, withdrawal/negative affect, and preoccupation/anticipation-map onto disturbances in three major neurocircuits (basal ganglia, extended amygdala, and frontal cortex, respectively), which correspond to three functional domains characterized by excessive incentive salience/habit formation, negative emotional states, and dysregulation of executive function [107-109]. Given the correlation between substance use and binge eating, this three-stage model implies the potential to further characterize dopamine function in the process of binge eating, which would ultimately facilitate the prevention and treatment of this problematic eating behavior.

\section{Conclusion}

In conclusion, although most studies have supported altered dopamine levels, dopamine activities, dopamine regulator levels/activities, or dopamine receptor availability/affinity related to binge eating, the direction of the alteration is unclear. Future studies may benefit from a careful control of confounding variables that may influence dopamine functioning (e.g. psychiatric diseases). Furthermore, longitudinal studies are needed to test whether there is a shift from hyperdopaminergic to hypodopaminergic state as binge eating progresses and whether individual genotypes modulate the relationship between dopamine and binge eating, which are two hypotheses that may potentially reconcile the inconsistent findings.

\section{Acknowledgements}

N/A.

\section{Authors' contributions}

YY conceptualized this paper, conducted the literature search, and was the major contributor in writing the manuscript. RM critically reviewed and edited the manuscript. SWG supervised the search process and critically reviewed and edited the manuscript. All authors read and approved the final manuscript.

\section{Funding}

This research received no specific grant from any funding agency, commercial or not-for-profit sectors.

\section{Availability of data and materials}

N/A.

\section{Declarations}

Ethics approval and consent to participate N/A. 


\section{Consent for publication}

N/A

\section{Competing interests}

All authors declared that they have no competing interests.

\section{Author details}

'School of Nursing, University of Rochester, 601 Elmwood Avenue, Rochester, NY 14642, USA. ${ }^{2}$ Brain and Cognitive Sciences, University of Rochester, 303F Meliora Hall, Rochester, NY 14627, USA

Received: 16 July 2021 Accepted: 6 January 2022

Published online: 28 January 2022

\section{References}

1. American Psychiatric Association. Diagnostic and statistical manual of mental disorders. 5th ed. Arlington: Author; 2013

2. Bertoli $\mathrm{S}$, Leone $\mathrm{A}$, Ponissi $\mathrm{V}$, et al. Prevalence of and risk factors for binge eating behaviour in 6930 adults starting a weight loss or maintenance programme. Public Health Nutr. 2016;19(1):71-7.

3. Salas-Wright CP, Vaughn MG, Miller DP, et al. Overeating and binge eating among immigrants in the United States: new terrain for the healthy immigrant hypothesis. Soc Psychiatry Psychiatr Epidemiol. 2019;54(8):1007-17.

4. Kessler RC, Berglund PA, Chiu WT, et al. The prevalence and correlates of binge eating disorder in the World Health Organization World Mental Health Surveys. Biol Psychiatry. 2013;73(9):904-14.

5. Udo T, Grilo CM. Prevalence and correlates of DSM-5-defined eating disorders in a nationally representative sample of U.S. adults. Biol Psychiatry. 2018;84(5):345-54.

6. Cossrow N, Pawaskar M, Witt EA, et al. Estimating the prevalence of binge eating disorder in a community sample from the United States: comparing DSM-IV-TR and DSM-5 Criteria. J Clin Psychiatry. 2016;77(8):e968-974

7. Linardon J, Wade TD. How many individuals achieve symptom abstinence following psychological treatments for bulimia nervosa? A meta-analytic review. Int J Eat Disord. 2018;51(4):287-94.

8. Goldschmidt AB, Smith KE, Crosby RD, et al. Ecological momentary assessment of maladaptive eating in children and adolescents with overweight or obesity. Int J Eat Disord. 2018;51(6):549-57.

9. Witt AA, Lowe MR. Hedonic hunger and binge eating among women with eating disorders. Int J Eat Disord. 2014;47(3):273-80.

10. Furlong TM, Jayaweera HK, Balleine BW, Corbit LH. Binge-like consumption of a palatable food accelerates habitual control of behavior and is dependent on activation of the dorsolateral striatum. J Neurosci. 2014;34(14):5012-22.

11. Ciria LF, Watson P, Vadillo MA, Luque D. Is the habit system altered in individuals with obesity? A systematic review. Neurosci Biobehav Rev. 2021:128:621-32.

12. Reiter AM, Heinze HJ, Schlagenhauf F, Deserno L. Impaired flexible reward-based decision-making in binge eating disorder: evidence from computational modeling and functional neuroimaging. Neuropsychopharmacology. 2017;42(3):628-37.

13. Cury MEG, Berberian A, Scarpato BS, Kerr-Gaffney J, Santos FH, Claudino AM. Scrutinizing domains of executive function in binge eating disorder: a systematic review and meta-Analysis. Front Psychiatry. 2020;11:288.

14. Iceta $S$, Rodrigue $C$, Legendre $M$, et al. Cognitive function in binge eating disorder and food addiction: a systematic review and threelevel meta-analysis. Prog Neuropsychopharmacol Biol Psychiatry. 2021;111:110400

15. Dawe S, Loxton NJ. The role of impulsivity in the development of substance use and eating disorders. Neurosci Biobehav Rev. 2004;28(3):343-51.

16. Kessler RM, Hutson PH, Herman BK, Potenza MN. The neurobiological basis of binge-eating disorder. Neurosci Biobehav Rev. 2016;63:223-38.

17. Yin $\mathrm{HH}$, Ostlund SB, Knowlton BJ, Balleine BW. The role of the dorsomedial striatum in instrumental conditioning. Eur J Neurosci. 2005:22(2):513-23.
18. Yin $\mathrm{HH}$, Knowlton $\mathrm{BJ}$, Balleine BW. Lesions of dorsolateral striatum preserve outcome expectancy but disrupt habit formation in instrumental learning. Eur J Neurosci. 2004;19(1):181-9.

19. Bjorklund A, Dunnett SB. Dopamine neuron systems in the brain: an update. Trends Neurosci. 2007:30(5):194-202.

20. Olney JJ, Warlow SM, Naffziger EE, Berridge KC. Current perspectives on incentive salience and applications to clinical disorders. Curr Opin Behav Sci. 2018;22:59-69.

21. Berridge KC, Robinson TE, Aldridge JW. Dissecting components of reward: "liking", "wanting", and learning. Curr Opin Pharmacol. 2009;9(1):65-73.

22. Berridge KC, Ho CY, Richard JM, DiFeliceantonio AG. The tempted brain eats: pleasure and desire circuits in obesity and eating disorders. Brain Res. 2010;1350:43-64.

23. Born JM, Lemmens SGT, Martens MJI, Formisano R, Goebel R, Westerterp-Plantenga MS. Brain representation of liking and wanting as a function of hunger and satiety. Appetite. 2010;54:635

24. Trujillo P, van Wouwe NC, Lin YC, et al. Dopamine effects on frontal cortical blood flow and motor inhibition in Parkinson's disease. Cortex. 2019:115:99-111.

25. Servant M, van Wouwe N, Wylie SA, Logan GD. A model-based quantification of action control deficits in Parkinson's disease. Neuropsychologia. 2018;111:26-35

26. Jongkees BJ. Baseline-dependent effect of dopamine's precursor L-tyrosine on working memory gating but not updating. Cogn Affect Behav Neurosci. 2020;20(3):521-35.

27. Bezu M, Maliković J, Kristofova M, et al. Spatial working memory in male rats: pre-experience and task dependent roles of dopamine D1- and D2-like receptors. Front Behav Neurosci. 2017:11:196.

28. Meder D, Herz DM, Rowe JB, Lehéricy S, Siebner HR. The role of dopamine in the brain - lessons learned from Parkinson's disease. Neuroimage. 2019;190:79-93.

29. Belin-Rauscent A, Everitt BJ, Belin D. Intrastriatal shifts mediate the transition from drug-seeking actions to habits. Biol Psychiatry. 2012;72(5):343-5.

30. Wickens JR, Horvitz JC, Costa RM, Killcross S. Dopaminergic mechanisms in actions and habits. J Neurosci. 2007;27(31):8181-3.

31. Guo J, Simmons WK, Herscovitch P, Martin A, Hall KD. Striatal dopamine D2-like receptor correlation patterns with human obesity and opportunistic eating behavior. Mol Psychiatry. 2014;19(10):1078-84.

32. Buckholtz JW, Treadway MT, Cowan RL, et al. Dopaminergic network differences in human impulsivity. Science. 2010;329(5991):532.

33. Djamshidian A, O'Sullivan SS, Foltynie T, et al. Dopamine agonists rather than deep brain stimulation cause reflection impulsivity in Parkinson's disease. J Parkinsons Dis. 2013;3(2):139-44.

34. Missale C, Nash SR, Robinson SW, Jaber M, Caron MG. Dopamine receptors: from structure to function. Physiol Rev. 1998;78(1):189-225.

35. Beaulieu JM, Gainetdinov RR. The physiology, signaling, and pharmacology of dopamine receptors. Pharmacol Rev. 2011;63(1):182-217.

36. Singh U, Kumar S, Shelkar GP, et al. Transient receptor potential vanilloid 3 (TRPV3) in the ventral tegmental area of rat: role in modulation of the mesolimbic-dopamine reward pathway. Neuropharmacology. 2016:110(Pt A):198-210.

37. Skibicka KP, Shirazi RH, Rabasa-Papio C, et al. Divergent circuitry underlying food reward and intake effects of ghrelin: dopaminergic VTA-accumbens projection mediates ghrelin's effect on food reward but not food intake. Neuropharmacology. 2013;73:274-83.

38. Carboni E, Silvagni A. Dopamine reuptake by norepinephrine neurons: exception or rule? Crit Rev Neurobiol. 2004;16(1-2):121-8.

39. Beaulieu J-M, Espinoza S, Gainetdinov RR. Dopamine receptors IUPHAR Review 13. Br J Pharmacol. 2015;172(1):1-23.

40. Avena NM, Bocarsly ME. Dysregulation of brain reward systems in eating disorders: neurochemical information from animal models of binge eating, bulimia nervosa, and anorexia nervosa. Neuropharmacology. 2012;63(1):87-96

41. Bello NT, Hajnal A. Dopamine and binge eating behaviors. Pharmacol Biochem Behav. 2010;97(1):25-33.

42. Broft Al, Berner LA, Martinez D, Walsh BT. Bulimia nervosa and evidence for striatal dopamine dysregulation: a conceptual review. Physiol Behav. 2011;104(1):122-7. 
43. Hadad NA, Knackstedt LA. Addicted to palatable foods: comparing the neurobiology of Bulimia Nervosa to that of drug addiction. Psychopharmacology. 2014;231(9):1897-912.

44. Michaelides M, Thanos PK, Volkow ND, Wang GJ. Dopamine-related frontostriatal abnormalities in obesity and binge-eating disorder: emerging evidence for developmental psychopathology. Int Rev Psychiatry. 2012;24(3):211-8

45. Naef L, Pitman KA, Borgland SL. Mesolimbic dopamine and its neuromodulators in obesity and binge eating. CNS Spectr. 2015;20(6):574-83.

46. Volkow ND, Wang GJ, Fowler JS, et al. Imaging endogenous dopamine competition with [11C]raclopride in the human brain. Synapse. 1994;16(4):255-62.

47. Broft A, Shingleton R, Kaufman J, et al. Striatal dopamine in bulimia nervosa: a PET imaging study. Int J Eat Disord. 2012;45(5):648-56.

48. Wang GJ, Geliebter A, Volkow ND, et al. Enhanced striatal dopamine release during food stimulation in binge eating disorder. Obesity (Silver Spring). 2011;19(8):1601-8.

49. Majuri J, Joutsa J, Johansson J, et al. Dopamine and opioid neurotransmission in behavioral addictions: a comparative PET study in pathological gambling and binge eating. Neuropsychopharmacology. 2017;42(5):1169-77.

50. D'Ardenne K, McClure SM, Nystrom LE, Cohen JD. BOLD responses reflecting dopaminergic signals in the human ventral tegmental area. Science. 2008:319(5867):1264-7.

51. Guitart-Masip M, Salami A, Garrett D, Rieckmann A, Lindenberger U, Bäckman L. BOLD variability is related to dopaminergic neurotransmission and cognitive aging. Cereb Cortex. 2016;26(5):2074-83.

52. Frank GK, Reynolds JR, Shott ME, O'Reilly RC. Altered temporal difference learning in bulimia nervosa. Biol Psychiatry. 2011;70(8):728-35.

53. Mueller SV, Morishima Y, Schwab S, Wiest R, Federspiel A, Hasler G. Neural correlates of impaired reward-effort integration in remitted bulimia nervosa. Neuropsychopharmacology. 2018;43(4):868-76.

54. Dodds CM, O'Neill B, Beaver J, et al. Effect of the dopamine D3 receptor antagonist GSK598809 on brain responses to rewarding food images in overweight and obese binge eaters. Appetite. 2012;59(1):27-33.

55. Chawla A, Cordner ZA, Boersma G, Moran TH. Cognitive impairment and gene expression alterations in a rodent model of binge eating disorder. Physiol Behav. 2017;180:78-90.

56. Corwin RL, Wojnicki FH, Zimmer DJ, et al. Binge-type eating disrupts dopaminergic and GABAergic signaling in the prefrontal cortex and ventral tegmental area. Obesity (Silver Spring). 2016;24(10):2118-25.

57. Frieling H, Römer KD, Scholz S, et al. Epigenetic dysregulation of dopaminergic genes in eating disorders. Int J Eat Disord. 2010;43(7):577-83.

58. Davis C, Levitan RD, Yilmaz Z, Kaplan AS, Carter JC, Kennedy JL. Binge eating disorder and the dopamine D2 receptor: genotypes and sub-phenotypes. Prog Neuropsychopharmacol Biol Psychiatry. 2012;38(2):328-35.

59. Davis C, Loxton NJ, Levitan RD, Kaplan AS, Carter JC, Kennedy JL. "Food addiction" and its association with a dopaminergic multilocus genetic profile. Physiol Behav. 2013;118:63-9.

60. Gonzalez LM, Mota-Zamorano S, Garcia-Herraiz A, Lopez-Nevado E, Gervasini G. Genetic variants in dopamine pathways affect personality dimensions displayed by patients with eating disorders. Eat Weight Disord. 2019;26:93-101.

61. Thaler L, Groleau P, Badawi G, et al. Epistatic interactions implicating dopaminergic genes in bulimia nervosa (BN): relationships to eatingand personality-related psychopathology. Prog Neuropsychopharmacol Biol Psychiatry. 2012;39(1):120-8

62. Gervasini G, Gonzalez LM, Gamero-Villarroel C, et al. Effect of dopamine receptor D4 (DRD4) haplotypes on general psychopathology in patients with eating disorders. Gene. 2018;654:43-8.

63. Yilmaz Z, Kaplan AS, Levitan RD, Zai CC, Kennedy JL. Possible association of the DRD4 gene with a history of attention-deficit/hyperactivity disorder in women with bulimia nervosa. Int J Eat Disord. 2012;45(4):622-5.

64. Gervasini G, Gonzalez LM, Mota-Zamorano S, et al. Association of COMT Val158Met polymorphism with psychopathological symptoms in patients with eating disorders. Curr Mol Med. 2018;18(1):65-70.

65. Donofry SD, Roecklein KA, Wildes JE, Miller MA, Flory JD, Manuck SB. COMT met allele differentially predicts risk versus severity of aberrant eating in a large community sample. Psychiatry Res. 2014:220(1-2):513-8.
66. Yilmaz Z, Kaplan AS, Zai CC, Levitan RD, Kennedy JL. COMT Val158Met variant and functional haplotypes associated with childhood ADHD history in women with bulimia nervosa. Prog Neuropsychopharmacol Biol Psychiatry. 2011;35(4):948-52.

67. Jönsson EG, Nöthen MM, Grünhage F, et al. Polymorphisms in the dopamine D2 receptor gene and their relationships to striatal dopamine receptor density of healthy volunteers. Mol Psychiatry. 1999;4(3):290-6.

68. Ritchie T, Noble EP. Association of seven polymorphisms of the D2 dopamine receptor gene with brain receptor-binding characteristics. Neurochem Res. 2003;28(1):73-82.

69. Hirvonen M, Laakso A, Nagren K, Rinne JO, Pohjalainen T, Hietala J. C957T polymorphism of the dopamine D2 receptor (DRD2) gene affects striatal DRD2 availability in vivo. Mol Psychiatry. 2004;9(12):1060-1.

70. Parsian A, Cloninger CR, Zhang ZH. Functional variant in the DRD2 receptor promoter region and subtypes of alcoholism. Am J Med Genet. 2000;96(3):407-11.

71. Savitz J, Hodgkinson CA, Martin-Soelch C, et al. The functional DRD3 Ser9Gly polymorphism (rs6280) is pleiotropic, affecting reward as well as movement. PLOS ONE. 2013;8(1):e54108.

72. Ding Y-C, Chi H-C, Grady DL, et al. Evidence of positive selection acting at the human dopamine receptor D4 gene locus. PNAS. 2002;99(1):309.

73. Mill J, Asherson P, Browes C, D'Souza U, Craig I. Expression of the dopamine transporter gene is regulated by the $3^{\prime}$ UTR VNTR: evidence from brain and lymphocytes using quantitative RT-PCR. Am J Med Genet. 2002;114(8):975-9.

74. Chen J, Lipska BK, Halim N, et al. Functional analysis of genetic variation in catechol-O-methyltransferase (COMT): effects on mRNA, protein, and enzyme activity in postmortem human brain. Am J Hum Genet. 2004;75(5):807-21.

75. Mineo D, Cacace F, Mancini M, et al. Dopamine drives binge-like consumption of a palatable food in experimental Parkinsonism. Mov Disord. 2019;34(6):821-31.

76. Grob S, Pizzagalli DA, Dutra SJ, et al. Dopamine-related deficit in reward learning after catecholamine depletion in unmedicated, remitted subjects with bulimia nervosa. Neuropsychopharmacology. 2012;37(8):1945-52.

77. Grob S, Stern J, Gamper L, et al. Behavioral responses to catecholamine depletion in unmedicated, remitted subjects with bulimia nervosa and healthy subjects. Biol Psychiatry. 2015;77(7):661-7.

78. Nasser JA, Del Parigi A, Merhige K, Wolper C, Geliebter A, Hashim SA. Electroretinographic detection of human brain dopamine response to oral food stimulation. Obesity (Silver Spring). 2013;21(5):976-80.

79. Guerdjikova Al, Mori N, Blom TJ, et al. Lisdexamfetamine dimesylate in binge eating disorder: a placebo controlled trial. Hum Psychopharmacol. 2016;31(5):382-91.

80. McElroy SL, Hudson JI, Mitchell JE, et al. Efficacy and safety of lisdexamfetamine for treatment of adults with moderate to severe binge-eating disorder: a randomized clinical trial. JAMA Psychiat. 2015;72(3):235-46.

81. Grilo CM, McElroy SL, Hudson Jl, et al. Efficacy and safety of dasotraline in adults with binge-eating disorder: a randomized, placebo-controlled fixed-dose clinical trial. CNS Spectr. 2020;81:1-10.

82. Lardeux S, Kim JJ, Nicola SM. Intermittent-access binge consumption of sweet high-fat liquid does not require opioid or dopamine receptors in the nucleus accumbens. Behav Brain Res. 2015;292:194-208.

83. Suarez-Ortiz JO, Cortes-Salazar F, Malagon-Carrillo AL, et al. Intra-accumbens raclopride administration prevents behavioral changes induced by intermittent access to sucrose solution. Front Neurosci. 2018;12:74

84. Amorim-Barbosa T, Serrao MP, Brandao I, Vieira-Coelho MA. CatecholO-methyltransferase activity in erythrocytes from patients with eating disorders. Eat Weight Disord. 2016;21(2):221-7.

85. Groleau P, Joober R, Israel M, Zeramdini N, DeGuzman R, Steiger H. Methylation of the dopamine D2 receptor (DRD2) gene promoter in women with a bulimia-spectrum disorder: associations with borderline personality disorder and exposure to childhood abuse. J Psychiatr Res. 2014:48(1):121-7.

86. Vaz-Leal FJ, Rodriguez-Santos L, Garcia-Herraiz MA, Ramos-Fuentes MI. Neurobiological and psychopathological variables related to emotional instability: a study of their capability to discriminate patients with bulimia nervosa from healthy controls. Neuropsychobiology. 2011:63(4):242-51. 
87. Blum K, Chen AL-C, Braverman ER, et al. Attention-deficit-hyperactivity disorder and reward deficiency syndrome. Neuropsychiatr Dis Treat. 2008;4(5):893-918.

88. Dunlop BW, Nemeroff CB. The role of dopamine in the pathophysiology of depression. Arch Gen Psychiatry. 2007;64(3):327-37.

89. Egerton A, Valmaggia LR, Howes OD, et al. Adversity in childhood linked to elevated striatal dopamine function in adulthood. Schizophr Res. 2016;176(2-3):171-6.

90. Mele G, Alfano V, Cotugno A, Longarzo M. A broad-spectrum review on multimodal neuroimaging in bulimia nervosa and binge eating disorder. Appetite. 2020;151:104712.

91. Schienle A, Schafer A, Hermann A, Vaitl D. Binge-eating disorder: reward sensitivity and brain activation to images of food. Biol Psychiatry. 2009;65(8):654-61.

92. Lee JE, Namkoong K, Jung YC. Impaired prefrontal cognitive control over interference by food images in binge-eating disorder and bulimia nervosa. Neurosci Lett. 2017;651:95-101.

93. Vaz-Leal FJ, Rodriguez-Santos L, Garcia-Herraiz MA, Ramos-Fuentes MI. Neurobiological and psychopathological variables related to emotional instability: a study of their capability to discriminate patients with bulimia nervosa from healthy controls. Neuropsychobiology. 2011;63(4):242-51.

94. Hildebrandt BA, Sinclair EB, Sisk CL, Klump KL. Exploring reward system responsivity in the nucleus accumbens across chronicity of binge eating in female rats. Int J Eat Disord. 2018;51(8):989-93.

95. Burke MV, Small DM. Effects of the modern food environment on striatal function, cognition and regulation of ingestive behavior. Curr Opin Behav Sci. 2016;9:97-105.

96. Stice E, Burger K. Neural vulnerability factors for obesity. Clin Psychol Rev. 2019;68:38-53.

97. Stice $\mathrm{E}$, Burger $\mathrm{KS}$, Yokum $\mathrm{S}$. Reward region responsivity predicts future weight gain and moderating effects of the TaqIA allele. J Neurosci. 2015:35(28):10316-24.

98. Ferriter C, Ray LA. Binge eating and binge drinking: an integrative review. Eat Behav. 2011;12(2):99-107.

99. Becker DF, Grilo CM. Comorbidity of mood and substance use disorders in patients with binge-eating disorder: associations with personality disorder and eating disorder pathology. J Psychosom Res. 2015;79(2):159-64.

100. Gearhardt AN, Davis C, Kuschner R, Brownell KD. The addiction potential of hyperpalatable foods. Curr Drug Abuse Rev. 2011;4(3):140-5.

101. Nutt DJ, Lingford-Hughes A, Erritzoe D, Stokes PR. The dopamine theory of addiction: 40 years of highs and lows. Nat Rev Neurosci. 2015;16(5):305-12.

102. Solinas $M$, Belujon $P$, Fernagut $P O$, Jaber M, Thiriet N. Dopamine and addiction: what have we learned from 40 years of research. J Neural Transm (Vienna). 2019;126(4):481-516.

103. Volkow ND, Wise RA, Baler R. The dopamine motive system: implications for drug and food addiction. Nat Rev Neurosci. 2017;18(12):741-52.

104. Koob GF, Volkow ND. Neurobiology of addiction: a neurocircuitry analysis. Lancet Psychiatry. 2016;3(8):760-73.

105. Koob GF, Volkow ND. Neurocircuitry of addiction. Neuropsychopharmacology. 2010;35(1):217-38

106. Davis C, Zai C, Levitan RD, et al. Opiates, overeating and obesity: a psychogenetic analysis. Int J Obes (Lond). 2011:35(10):1347-54

107. Porrino $\amalg$, Smith HR, Nader MA, Beveridge TJ. The effects of cocaine: a shifting target over the course of addiction. Prog Neuropsychopharmacol Biol Psychiatry. 2007;31 (8):1593-600.

108. Vollstädt-Klein S, Wichert S, Rabinstein J, et al. Initial, habitual and compulsive alcohol use is characterized by a shift of cue processing from ventral to dorsal striatum. Addiction. 2010;105(10):1741-9.

109. Voon V, Grodin E, Mandali A, et al. Addictions neuroimaging assessment (ANIA): towards an integrative framework for alcohol use disorder. Neurosci Biobehav Rev. 2020;113:492-506

\section{Publisher's Note}

Springer Nature remains neutral with regard to jurisdictional claims in published maps and institutional affiliations.

Ready to submit your research? Choose BMC and benefit from:

- fast, convenient online submission

- thorough peer review by experienced researchers in your field

- rapid publication on acceptance

- support for research data, including large and complex data types

- gold Open Access which fosters wider collaboration and increased citations

- maximum visibility for your research: over $100 \mathrm{M}$ website views per year

At BMC, research is always in progress.

Learn more biomedcentral.com/submissions 